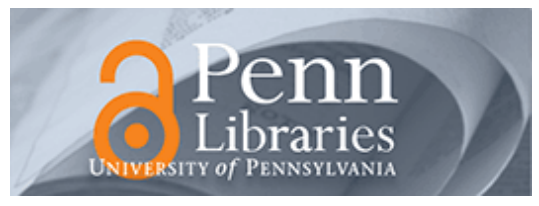

University of Pennsylvania

ScholarlyCommons

Finance Papers

Wharton Faculty Research

2016

\title{
The Time-Money Trade-Off for Entrepreneurs: When to Hire the First Employee?
}

Onesun Steve Yoo

Guillaume Roels

Charles J. Corbett

Follow this and additional works at: https://repository.upenn.edu/fnce_papers

Part of the Finance and Financial Management Commons

\section{Recommended Citation}

Yoo, O. S., Roels, G., \& Corbett, C. J. (2016). The Time-Money Trade-Off for Entrepreneurs: When to Hire the First Employee?. Manufacturing \& Service Operations Management, 18 (4), 559-569. http://dx.doi.org/ $10.1287 / \mathrm{msom} .2016 .0587$

This paper is posted at ScholarlyCommons. https://repository.upenn.edu/fnce_papers/138

For more information, please contact repository@pobox.upenn.edu. 


\title{
The Time-Money Trade-Off for Entrepreneurs: When to Hire the First Employee?
}

\begin{abstract}
For many early-stage entrepreneurs, hiring the first employee is a critical step in the firm's growth. Doing so often requires significant time and monetary investments. To understand the trade-offs involved in deciding when to hire the first employee and how hiring differs in entrepreneurial settings from more established firm settings, we present a simple growth model that depends on two critical inputs for revenue generation: the entrepreneur's time and money. We show that without hiring, the entrepreneur's time eventually becomes more valuable than money in contributing to the firm's growth. In that context, the value of the employee is driven by how much relief he provides to the entrepreneur. We characterize the optimal timing of hiring in terms of the firm's cash position and how the firm is affected if it requires an upfront fixed investment in time and/or money. We find that the upfront investment in time needed for hiring cannot be converted to an equivalent upfront investment in money and that mistiming hiring can be very costly, especially when these upfront investments are high.
\end{abstract}

\section{Keywords}

entrepreneurial operations, hiring, optimal stopping problem

Disciplines

Business | Finance and Financial Management 


\title{
The Time-Money Trade-Off for Entrepreneurs: When to Hire the First Employee?
}

\author{
Onesun Steve Yoo \\ Department of Management Science and Innovation, University College London, \\ London WC1E 6BT, United Kingdom, onesun.yoo@ucl.ac.uk \\ Guillaume Roels \\ UCLA Anderson School of Management, 110 Westwood Plaza, Los Angeles, CA 90095, USA, \\ guillaume.roels@anderson.ucla.edu \\ Charles J. Corbett \\ UCLA Anderson School of Management, 110 Westwood Plaza, Los Angeles, CA 90095, USA, \\ charles.corbett@anderson.ucla.edu
}

\begin{abstract}
Entrepreneurs need to invest money and time to grow their firms. Both money and time are often scarce, but the nature of these two resources is fundamentally different. Considering a small, fast-growing entrepreneurial firm, we show that the firm's key bottleneck resource shifts from money to time as the firm grows, and we characterize hiring as an operational mechanism for trading money for time to accelerate growth. The optimal time for entrepreneurs to hire their first employee occurs as soon as their available cash is sufficiently large, in order to alleviate the time bottleneck. We show that the cash threshold determined from a one-step look-ahead policy is optimal when growth is deterministic and performs well even when that is not the case. We find that hiring costs delay hiring, whereas hiring times may either delay or expedite hiring, because of the non-trivial tradeoff between the need to preserve the growth momentum and the need to hire before the opportunity cost of time becomes too large. Hence, time and money should be managed as distinct resources in growth-oriented firms.
\end{abstract}

Key words: Entrepreneurial Operations, Capacity Investment, Hiring, Bottleneck, Dynamic Programming, Supermodularity, Heuristic.

"There are only three fundamental resources you will be working with to achieve your entrepreneurial goals: time, people, and money. As an entrepreneur, you can usually trade one for the others." (Burgstone and Murphy 2012, Breakthrough Entrepreneurship, p. 156)

\section{Introduction}

For many entrepreneurs presented with a growth opportunity, realizing that growth is not without challenges. The firm often lacks the necessary resources and faces a realistic possibility of imminent failure (Hamermesh et al. 2005). Scaling the business and capitalizing on the growth opportunity during this phase strongly depends on the entrepreneur's ability to manage the firm's limited resources. 
Among the scarce resources, two particularly fundamental ones are money and time. A phase of high growth puts severe pressure on the entrepreneur's financial resources (Hambrick and Crozier 1985) and many entrepreneurs are unable to scale their business due to funding difficulties (Evans and Jovanovic 1989). To fund their growth, many firms reinvest their earnings (Ebben and Johnson 2006) and often borrow the necessary funds (Berger and Udell 1998). At the same time, as the firm expands, an increasing number of tasks require the entrepreneur's attention, now putting pressure on her time and processing capacity (Gifford 1992). Some activities cannot be easily delegated, so entrepreneurs often find themselves becoming the bottleneck resource of their firms (Martin and Papadimitriou 2009). When the entrepreneur's time is the bottleneck, hiring can be viewed as a way to alleviate that constraint so as to sustain the firm's growth, as illustrated by the following quote: "Typically, when a company is founded by a group of motivated and bright individuals, the founding team is involved in most aspects of the company's operations in the early days ... as the company grows, it must hire new employees, because the founding team is capacity constrained and does not have the bandwidth to be involved in all aspects of the company operations" (Krishnan 2013, p. 3).

While time and money are both necessary resources for growth, they are inherently different. In this paper we explore how entrepreneurs can trade time and money, and explore the consequences of the inherent asymmetry between the two. First, money, unlike time, is fungible. Whereas money can be accumulated (or borrowed) across periods, time is only available in a limited budget each period (e.g., 30 days per month) and is perishable. Although activities can be shifted between periods, leftover time cannot be stored nor can extra time be created. Second, the result of the firm's core activity is money, not time. The output of the firm in one period can be reinvested into the firm in the form of money in the next period but not in the form of time. To better manage the two resources, one must first understand the implications of these properties of time and money.

How does the severity of the time and money constraints evolve during the growth phase? To address this question, we introduce a finite-horizon growth model for entrepreneurial firms in which revenue in each period is a function of two complementary inputs: money and time. The constraint on time represents the amount of time that exists each period (e.g., 30 days per month), and the constraint on money represents the amount of money available in the firm (initial starting capital and accumulated revenue). We examine the evolution of the shadow prices of time and money and show that the bottleneck always shifts from money to time, meaning that time will eventually become more valuable than money as the firm grows, an immediate consequence of the asymmetry between the two. We introduce hiring as a mechanism to alleviate the time bottleneck (Goldratt 2004), trading off money (wages) for additional time (via delegation) to allow faster growth. 
When should entrepreneurs hire their first employee? Hiring too early or too late can inhibit growth: "Too often, those who bring the business to the success stage are unsuccessful... either because they try to grow too fast and run out of cash..., or are unable to delegate effectively enough to make the company work" (Churchill and Lewis 1983, p. 9). In our context, hiring an employee represents an agreement to trade off a fixed amount of money for a fixed amount of time each period for the remainder of the horizon. Moreover, hiring (and training) often entails fixed costs of money and time, referred to as hiring cost and hiring time, which temporarily slows down the firm's growth (Tansky and Heneman 2006, Aldrich and Fiol 1994, Collins and Clark 2003, Williamson 2000). Furthermore, hiring may increase the probability of bankruptcy. In such a setting, with growth and uncertainty, there is limited guidance on when an entrepreneur should hire.

We define the timing of hiring in terms of a cash threshold defined by the one-stage-look-ahead $(O S L A)$ rule. We show that this policy is optimal when growth is deterministic and numerically performs well when that is not the case (Babich and Sobel 2004). The high performance of the $O S L A$ policy is robust to the problem parameters in our growth setting.

Focusing on the OSLA hiring policy, we examine how various factors influence the timing of hiring. We find that hiring is delayed when hiring costs are higher. However, greater hiring time can either expedite or delay hiring, because of two conflicting effects. On the one hand, increased hiring time diverts more valuable time away from growth activities, which slows growth, pushing for later hiring. On the other hand, it may be more desirable to incur a larger hiring time when time is less valuable, pushing for earlier hiring. Hence, time and money should be considered as distinct resources in growth-oriented firms. We replicate the analysis to investigate the optimal timing of firing and show that the insights mirror those for hiring. We numerically examine hiring with and without firing, and find that the option of firing does not materially influence the timing of hiring.

This paper is organized as follows. We review related literature in $\S 2$. In $\S 3$, we introduce the growth model and characterize the shift in bottleneck from money to time. In $\S 4$, we present the hiring model, characterize the OSLA hiring and firing policies separately, study their sensitivity, and demonstrate their optimality under certain conditions. We show numerically in $\S 5$ that the $O S L A$ policy performs well in general, and we conclude in $\S 6$. All proofs appear in the appendix.

\section{Related Literature}

We draw on three strands of literature: that on entrepreneurship and growth, the emerging literature on entrepreneurial operations, and that on capacity expansion. 


\subsection{Bottlenecks in Growth-Oriented Entrepreneurial Firms}

Firms typically go through several distinct phases in their life cycles from being a start-up to an established firm, each with its own specific objectives and constraints (Quinn and Cameron 1983). Typically, entrepreneurial firms initially face considerable uncertainty, and their goal is to learn and to innovate a viable product while acquiring necessary funding to survive (Jovanovic 1982). However, once they have learned about their market, true costs, and relative efficiency, the firms' primary concern becomes centered around growth (Quinn and Cameron 1983).

Maximizing growth during this phase strongly depends on the entrepreneur's ability to manage the firm's limited resources. Some authors identify cash as being the main constraining factor for growth (e.g., Hambrick and Crozier 1985, Evans and Jovanovic 1989, Ebben and Johnson 2006), whereas others identify the entrepreneur herself as the main bottleneck (Cressy 1996, Martin and Papadimitriou 2009), given that growth creates additional demands for the entrepreneur's attention and time (Gifford 1992). In line with the latter school of thought, how entrepreneurs allocate their time has received recent interest from the entrepreneurship literature (Lévesque and Schade 2005, Mueller et al. 2012). In the same spirit, Yoo et al. (2011) examine how they should allocate their time between process improvement and revenue growth.

In this paper, we unify the money-focused and time-focused viewpoints by demonstrating that both time and money are bottlenecks, but at different stages of the firm's growth. Considering a similar trade-off, Lévesque and MacCrimmon (1997) investigate how much time entrepreneurs should allocate to the venture initiation when they have regular hourly wage jobs. Similar to our model, time and money are assumed to be complementary. In their model, it is the wage job opportunity, and not hiring, that substitutes time for money. In contrast, we focus here on venture growth, and not initiation, and consider hiring as a one-time, irreversible decision to increase time; accordingly, properly timing hiring is key to achieve successful growth.

\subsection{Entrepreneurial Operations and Finance}

Many entrepreneurial firms face high uncertainty and lack financial resources, resulting in a high probability of failure. A growing body of operations management literature on entrepreneurial firms addresses these key issues.

2.2.1. Reducing Bankruptcy Probability. Some studies examine how operational decisions can minimize the likelihood of bankruptcy. When the firm's objective is to maximize survival probability, Archibald et al. (2002) show that inventory decisions should be more conservative and Swinney et al. (2011) examine a start-up's timing of capacity investments when competing against established firms. Tanrisever et al. (2012) examine the decision to invest in process improvement under the threat of bankruptcy. Unlike some of these works in which avoiding bankruptcy is the 
objective, we consider bankruptcy as a terminating condition, and our objective is growth, similar to maximizing the expected value of payoff in IPO (Babich and Sobel 2004).

2.2.2. Relaxing Financial Constraints. Many studies address the financing challenges faced by startups and fast growing companies. Buzacott and Zhang (2004) examine how asset-based financing can be used to manage their operations. Li et al. (2009) acknowledge the considerable interaction between the operations policy and the financing decisions for cash-constrained small growing firms and examine the impact of coordinating them. They find that the production and borrowing policy that maximizes the long-term value of dividends while avoiding bankruptcy is myopic. We obtain a similar result with the objective of maximizing the firm's long-term cash position. Sobel and Turcic (2007) examine how to use credit to better manage resources in nascent firms and show that the benefit from coordinating finance and operations is greater for smaller firms. Xu and Birge (2006) show that operational and financial decisions must be made jointly when capital markets are imperfect, i.e., in the presence of taxes and bankruptcy costs, and Dada and $\mathrm{Hu}(2008)$ and Kouvelis and Zhao (2011) further extend this by considering strategic interactions between the bank and the firm, and for the latter, a supplier.

We contribute to the literature on financing operations in two ways. First, we consider a nonfungible resource, namely time, as a potential bottleneck in addition to money. In contrast, most of the literature on financing operations focuses on the interplay between two substitutable and fungible resources (e.g., cash and inventory). Second, given that the time span of hiring decisions is typically longer than that of inventory decisions (Holt et al. 1960) we adopt a more tactical perspective on the operations of entrepreneurial firms.

\subsection{Capacity Expansion and Production Planning}

Hiring (and delegating tasks) in small firms increases the available time for the entrepreneur, enhancing the firm's capacity to grow. According to Dixit and Pindyck (1994), capacity decisions share three important characteristics: (i) investments are partially or completely irreversible, (ii) there exists uncertainty over future rewards, and (iii) there is leeway in the timing of investment. Our decision of when to hire a permanent employee under uncertainty in future rewards shares all three characteristics, so it relates to the extensive operations literature on capacity expansion (Luss 1982, Van Mieghem 2003). This literature typically considers a large firm in which exogenous demand is assumed to increase, either deterministically (Manne 1961) or stochastically (Luss 1982).

We contribute to this literature by presenting a different type of capacity expansion for growing firms. First, we allow capacity expansion to cost both time and money, unlike traditional models in which the expansion cost is purely monetary (Ye and Duenyas 2007). We show that hiring times 
and hiring costs have different effects on the timing of hiring: in the small growing firm setting, time and money must not be aggregated as is often implicitly done for established firms.

Second, we demonstrate a fundamental bottleneck shift between time (capacity) and money as the firm grows. Most of the literature on capacity expansion focuses only on capacity as a potential bottleneck, with a few exceptions that consider both capacity and money. Angelus and Porteus (2002) characterize the optimal capacity expansion and production plan over a product lifecycle with inventory carry-over. Although finished-good inventories and capacity can be likened to money and time in our model, they are substitutes, whereas money and time are complementary, fundamentally changing the nature of the trade-off. By contrast, Babich and Sobel (2004) focus on the interplay between raw material inventories and manufacturing capacity, which are complementary. We adopt a similar model, but focus on the optimal timing of hiring, whereas they focus on the optimal timing of an IPO. We complement their model by adopting a more tactical view on entrepreneurial operations and by demonstrating how the bottleneck shifts from one resource to another.

Our hiring decision also relates to the rich staffing literature, including the production smoothing models. Holt et al. (1960) and Bitran et al. (1981) propose a mathematical programming model to minimize the long-run costs of overtime/idle time and hiring costs under nonstationary deterministic demand. Similarly, we consider here a nonstationary planning horizon in which growth is expected. See Silver et al. (1998) for a review of aggregate production planning models. The literature on the operations of staffing considers how many employees to hire taking hiring fixed costs into account (Gans and Zhou 2002). We allow for hiring times as well as costs, but focus on hiring a single employee, in line with the realities of small growing firms.

\section{A Dynamic Model of Entrepreneurial Growth}

Here we introduce a dynamic model of entrepreneurial growth relying on two key complementary resources, time and money.

\section{1. $\quad$ Model}

Consider a risk-neutral entrepreneur who seeks to maximize her firm's expected cash position after $N$ periods (e.g., a few years). In each period $t$ (e.g., a month), she must decide how much of her time $\left(T_{t}\right)$ and how much money $\left(M_{t}\right)$ to invest in the firm given her time available $\left(J_{t}\right)$, the firm's current cash position $\left(I_{t}\right)$, and the state of the economy $\left(Z_{t}\right)$, assumed for simplicity to be unidimensional.

In any period, the operating profit $R\left(M_{t}, T_{t}, Z_{t}\right)$ depends on the money $\left(M_{t}\right)$ and time $\left(T_{t}\right)$ invested and the state of the economy $\left(Z_{t}\right)$. We assume that $R\left(M_{t}, T_{t}, Z_{t}\right)$ is (weakly) increasing, is concave in $M_{t}$ and in $T_{t}$, and has increasing differences in $\left(M_{t}, T_{t}\right)$. That is, more resources 
invested in the firm lead to greater profit, with diminishing returns. Similarly, a higher state of the economy leads to greater profits. Time and money are complementary, so the marginal return on investment in one is increasing in the investment in the other. We also assume that both resources are necessary for growth; specifically, $R(M, 0, Z)=R(0,0, Z)$ and $R(0, T, Z)=R(0,0, Z)$ for all $M, T, Z$. Finally, we assume that $\lim _{M \rightarrow \infty} \partial R(M, T, Z) / \partial M=\lim _{T \rightarrow \infty} \partial R(M, T, Z) / \partial T=0$, i.e., the marginal returns on investments of one resource become negligible beyond some point if the other resource remains finite. These assumptions are consistent with earlier work; e.g., Lévesque and MacCrimmon (1997) use $R(M, T, Z)=M^{\alpha} T^{1-\alpha}$ for some $\alpha, 0<\alpha<1$, while manufacturing models often consider $R(M, T, Z)=\min \{M, T, Z\}$ as discussed in Example 1 below; more generally, economic models often set $R(M, T, Z)=\left(a M^{\rho}+(1-a) T^{\rho}\right)^{q / \rho}$ (Dupuy and de Grip 2006).

Time is available only within a given budget $J_{t}$ (e.g., 30 days per month), so $T_{t} \leq J_{t}$. By contrast, money can be borrowed or saved. Hence, time and money are fundamentally different resources: time can be used to generate additional money (through $R\left(M_{t}, T_{t}, Z_{t}\right)$ ), whereas money cannot be used to generate additional time, unless the entrepreneur hires an employee.

If saved, money generates an interest $r$. Money can be borrowed at a cost $B\left(M_{t}, I_{t}, Z_{t}\right)$, which we assume nonnegative, increasing in $M_{t}$ and decreasing in $I_{t}$ and $Z_{t}$. The more cash is available to the firm, the lower the borrowing cost. We assume that $B\left(M_{t}, I_{t}, Z_{t}\right)$ has decreasing differences in $\left(M_{t}, I_{t}\right)$, is jointly convex in $\left(M_{t}, I_{t}\right)$, and is such that $B\left(I_{t}, I_{t}, Z_{t}\right)=0$. For instance, $B\left(M_{t}, I_{t}, Z_{t}\right)=$ $b\left(Z_{t}\right) \max \left\{0, M_{t}-I_{t}\right\}$, in which $b\left(Z_{t}\right)$ is a borrowing rate dependent on the state of the economy. ${ }^{1}$

The entrepreneur's cash position at the end of period $t, I_{t+1}$, is then equal to

$$
I_{t+1}=I_{t}(1+r)+\Pi\left(M_{t}, T_{t} \mid I_{t}, Z_{t}\right)
$$

in which $\Pi\left(M_{t}, T_{t} \mid I_{t}, Z_{t}\right)$ is the incremental profit obtained from operations relative to the future value of the current cash position, had it been invested at a rate $r$ :

$$
\Pi(M, T \mid I, Z) \equiv R(M, T, Z)-(1+r) M-B(M, I, Z)+r[M-I]^{+} .
$$

We assume that the state of the economy in period $t+1$ is a stochastic function of the state of the economy in period $t$ :

$$
Z_{t+1}=\phi_{t}\left(Z_{t}, \omega_{t}\right)
$$

\footnotetext{
${ }^{1}$ A state-dependent borrowing limit as in Buzacott and Zhang (2004), e.g., $M_{t} \leq \kappa\left(I_{t}, Z_{t}\right)$, can easily be incorporated in the borrowing cost by setting $B\left(M_{t}, I_{t}, Z_{t}\right)=\infty$ for all $M_{t}>\kappa\left(I_{t}, Z_{t}\right)$, as well as a cost of time $C(T)$ provided that $R(M, T, Z)$ is jointly concave in $(M, T)$. We ignore these features here to emphasize the greater fungibility of money relative to time. Moreover, Berger and Udell (1998) note that "it does not make it quite so difficult for young firms to obtain external finance, particularly debt from financial institutions, as is implied by the received wisdom about the financial growth cycle" (pp. 624-625).
} 
in which $\omega_{t}$ is a random variable with countable feasible set $\Omega_{t}$, i.e., $\omega_{t} \in \Omega_{t}$, as is commonly assumed (Babich and Sobel 2004, Sobel and Turcic 2007). When $\left|\Omega_{t}\right|=1$ for all $t$, the state of the economy evolves deterministically.

We assume that the firm goes bankrupt if its cash position falls below a certain threshold $L$. Archibald et al. (2002) and Li et al. (2009) consider $L$ equal to zero. In case of bankruptcy, the firm must pay bankruptcy costs $K \geq 0$, as in Swinney et al. (2011), Xu and Birge (2006), Li et al. (2009), and Kouvelis and Zhao (2011). We assume that bankruptcy costs are independent of the firm's cash level, but this can easily be relaxed using a model similar to Li et al. (2009). If $L=-\infty$, the firm never goes bankrupt, whereas if $K=0$, bankruptcy is costless. The firm is not allowed to borrow when it goes bankrupt, i.e., $B\left(M_{t}, I_{t}, Z_{t}\right)=\infty$ for all $I_{t}<L$ and all $M_{t}>0$.

The goal of the entrepreneur is to maximize the firm's expected cash position in period $N$, i.e., $\mathbb{E}\left[I_{N}\right]=(1+r)^{N} I_{0}+\sum_{k=0}^{N-1}(1+r)^{N-1-k} \mathbb{E}_{\omega_{k}}\left[\Pi\left(M_{k}, T_{k} \mid I_{k}, Z_{k}\left(\omega_{k}\right)\right)\right]$, by appropriately choosing the money and time investments $\left(M_{t}, T_{t}\right)$ in each period $t$ given the firm's cash position $\left(I_{t}\right)$ and the state of the economy $\left(Z_{t}\right)$. We formulate the problem as a finite-horizon dynamic program. Denoting $\delta \equiv 1 /(1+r)$, let $V_{t}^{0}\left(I_{t}, J_{t}, Z_{t}\right)$ be the entrepreneur's expected cash position in period $N$, given the firm's cash position $\left(I_{t}\right)$, available time $\left(J_{t}\right)$, and state of the economy $\left(Z_{t}\right)$ in period $t$ :

$$
\begin{array}{rlrl}
V_{t}^{0}\left(I_{t}, J_{t}, Z_{t}\right) & =\max _{M_{t}, T_{t} \leq J_{t}} \delta \mathbb{E}_{\omega_{t}}\left[V_{t+1}^{0}\left((1+r) I_{t}+\Pi\left(M_{t}, T_{t} \mid I_{t}, Z_{t}\right), J_{t+1}, \phi_{t}\left(Z_{t}, \omega_{t}\right)\right]\right. \\
V_{N}^{0}\left(I_{N}, J_{N}, Z_{N}\right) & =I_{N} & & \text { if } I_{t} \geq L, t=0, \ldots, N-1 \\
V_{t}^{0}\left(I_{t}, J_{t}, Z_{t}\right) & =-K & & \text { if } I_{N} \geq L \\
& & \text { if } I_{t}<L, t=0, \ldots, N .
\end{array}
$$

To avoid trivial cases, we assume that bankruptcy is never desirable, i.e., $V_{t}^{0}\left(I_{t}, J_{t}, Z_{t}\right)>-K$ for all $I_{t} \geq L$.

To illustrate the parallel between an entrepreneur's time and manufacturing capacity, we show how our model relates to that in Babich and Sobel (2004).

Example 1 (BABich AND Sobel 2004). Consider a manufacturing firm with capacity $J_{t}$ and cash position $I_{t}$ in period $t$. The firm must decide how much capacity to allocate for production $\left(T_{t}\right)$ and how much to invest in inventory of raw materials $M_{t}$ to satisfy a demand $Z_{t}$. If each unit of product costs $c$ in raw materials and can be sold at a price $p$, the firm's revenue in any given period is equal to $R\left(M_{t}, T_{t}, Z_{t}\right)=p \min \left\{M_{t} / c, T_{t}, Z_{t}\right\}$. Although the amount of capacity dedicated to production is limited by the firm's installed capacity, i.e., $T_{t} \leq J_{t}$, the firm may borrow additional cash at rate $b(I, J, Z, \eta)$ assumed to be decreasing in the firm's cash level $\left(I_{t}\right)$, capacity $\left(J_{t}\right)$, demand $\left(Z_{t}\right)$, and time-dependent risk-free discount factor $\left(\eta_{t}\right)$. Accordingly, the next-period cash position equals $I_{t+1}=R\left(M_{t}, T_{t}, Z_{t}\right)-M_{t}-b\left(I_{t}, J_{t}, Z_{t}, \eta_{t}\right)\left[M_{t}-I_{t}\right]^{+}$. Demand evolves randomly as $Z_{t+1}=a\left(Z_{t}\right)+\omega_{t}$, with $a^{\prime}() \geq$.0 , which is general enough to model mean-reverting processes such as $\operatorname{AR}(1)$. The evolution of $\eta_{t}$ follows a similar process. If the firm's cash position becomes negative, it cannot repay its loans and goes bankrupt at no cost, i.e., $L=0$ and $K=0$. 
Our growth model is thus highly consistent with the manufacturing-based model in Babich and Sobel (2004), notwithstanding modest differences such as a 2-dimensional state-of-the-economy variable, which could be incorporated easily. Our work generalizes the manufacturing-based models by adopting a generic functional form for $R(M, T, Z)$ : manufacturing-based models typically treat capacity and inventories as perfect complements, making the returns on capacity investments (piecewise) constant, while we do not restrict the return on time to be constant.

\subsection{Optimal Time and Money Investment Policy}

We next characterize the time and money investments that maximize the firm's expected cash position in period $N$. As in Li et al. (2009) and Sobel and Turcic (2007), we find that the value function is increasing in the cash position increment $\left(I_{t+1}-I_{t}\right)$, so it is optimal to myopically maximize the current cash position.

Lemma 1 (Optimal Myopic Time and Money Investments). The money and time investments that maximize the current period profit $\Pi\left(M, T \mid I_{t}, Z_{t}\right)$ also maximize expected final cash position $\delta \mathbb{E}_{\omega_{t}}\left[V_{t+1}^{0}\left((1+r) I_{t}+\Pi\left(M, T \mid I_{t}, Z_{t}\right), J_{t+1}, \phi_{t}\left(Z_{t}, \omega_{t}\right)\right]\right.$.

In general, the amount of cash invested in growth will depend on the amount of cash available. For instance, suppose that $B(M, I, Z)=b(Z)[M-I]^{+}$, with $b(Z)>r$. If the firm has limited cash available, it needs to borrow at a cost $b(Z)$ and will therefore invest a limited amount. If the firm has more cash available, it will not need to borrow, though it may still reinvest all its available cash in the business, referred to as bootstrapping (Ebben and Johnson 2006, Burgstone and Murphy 2012). Beyond a certain point, the firm will have so much cash that it will not need to reinvest it all and will therefore earn savings at a rate $r$. The money invested in the business may therefore depend on whether the firm borrows, bootstraps, or saves money.

Let

$$
\Pi^{*}\left(I_{t}, J_{t}, Z_{t}\right) \equiv \max _{M_{t}, T_{t} \leq J_{t}} \Pi\left(M_{t}, T_{t} \mid I_{t}, Z_{t}\right)
$$

denote the current period optimal profit. Lemma A-2 in the appendix shows that $\Pi^{*}\left(I_{t}, J_{t}, Z_{t}\right)$ is increasing, concave in $I_{t}$ and $J_{t}$, and has increasing differences in $\left(I_{t}, J_{t}\right)$. In other words, as the firm grows, it will operate at higher levels of revenue, necessitating higher monetary investments. Using Lemma 1, the value function (1) can be therefore be expressed in closed form:

$$
\begin{aligned}
V_{t}^{0}\left(I_{t}, J_{t}, Z_{t}\right) & =\delta \mathbb{E}_{\omega_{t}}\left[V_{t+1}^{0}\left((1+r) I_{t}+\Pi^{*}\left(I_{t}, J_{t}, Z_{t}\right), J_{t+1}, \phi_{t}\left(Z_{t}, \omega_{t}\right)\right]\right. & & \text { if } I_{t} \geq L, t=0, \ldots, N-1 \\
V_{N}^{0}\left(I_{N}, J_{N}, Z_{N}\right) & =I_{N} & & \text { if } I_{N} \geq L \\
V_{t}^{0}\left(I_{t}, J_{t}, Z_{t}\right) & =-K & & \text { if } I_{t}<L, t=0, \ldots, N .
\end{aligned}
$$




\subsection{Bottleneck Shift}

We next show that both time and money do constrain the firm's growth, but at different stages of the growth cycle, thereby reconciling the different opinions reviewed in $\S 2.1$ on what is the main bottleneck for small firms. We do this by characterizing the current-period shadow prices of money and time, $\mu_{t}$ and $\tau_{t}$, defined as the current-period expected marginal benefit of an increase in $I_{t}$ and $J_{t}$ respectively. Because an extra dollar in period $t$ gets carried over to $t+1$, unlike an extra hour, we subtract the extra dollar in period $t+1$ to focus only on the current-period benefits of an increase in time or money. Assuming differentiability, these marginal values can be expressed as:

$\mu_{t}=\frac{\partial}{\partial I_{t}} V_{t}^{0}\left(I_{t}, J_{t}, Z_{t}\right)-\delta \frac{\partial}{\partial I_{t+1}} \mathbb{E}_{\omega_{t}}\left\{V_{t+1}^{0}\left(I_{t+1}, J_{t+1}, \phi_{t}\left(Z_{t}, \omega_{t}\right)\right)\right\} \quad$ and $\quad \tau_{t}=\frac{\partial}{\partial J_{t}} V_{t}^{0}\left(I_{t}, J_{t}, Z_{t}\right)$.

Our first key result characterizes the dynamics of these shadow prices $\mu_{t}$ and $\tau_{t}$.

Proposition 1 (Bottleneck Shift). In any period $t$, there exist thresholds $\hat{I}\left(Z_{t}, J_{t}\right)$ and $\hat{J}\left(Z_{t}, I_{t}\right)$ such that $\tau_{t}<\mu_{t}$ if and only if $I_{t}<\hat{I}\left(Z_{t}, J_{t}\right)$ and $\tau_{t}<\mu_{t}$ if and only if $J_{t}>\hat{J}\left(Z_{t}, I_{t}\right)$.

Proposition 1 establishes that the bottleneck shifts from money to time as available cash $\left(I_{t}\right)$ increases or available time $\left(J_{t}\right)$ decreases. As the firm grows, cash becomes less of a constraint since the profit generated in previous periods can be accumulated and used to fuel growth in subsequent periods. By contrast, the entrepreneur's available time remains constrained, irrespective of past profits. Moreover, because time and money are complementary, the marginal value of time increases with the amount of cash available, making time even more valuable as the firm grows. This result is consistent with the notion that early financial investments matter in achieving high growth (Evans and Jovanovic 1989) and that time later becomes the bottleneck (Gifford 1992).

Figure 1 displays the shadow prices of money $\left(\mu_{0}\right)$ and time $\left(\tau_{0}\right)$ in period $t=0$ as a function of the initial cash position $I_{0}$. Money is the bottleneck $\left(\mu_{0}>\tau_{0}\right)$ when $I_{0}$ is low and time is $\left(\tau_{0}>\mu_{0}\right)$ when $I_{0}$ is high, and the unique bottleneck shift from money to time occurs when the cash position crosses the threshold $\hat{I}\left(Z_{0}, J_{0}\right)=26.4$. Although $\mu_{0}$ is monotonically decreasing, $\tau_{0}$ is not necessarily monotone in cash position $I_{0}$. Furthermore, the shadow prices can be decomposed into a product of two terms (see proof of Proposition 1): (i) the value of additional current-period cash or time on next period's cash $I_{1}$ and (ii) the value of additional next-period cash $I_{1}$ on the discounted cash in period $N, \delta^{N} I_{N}$, which is common to both shadow prices. Whereas the immediate effect of an increase in time or cash is monotone, respectively increasing and decreasing in $I_{0}$, the latter effect may not be monotone due to bankruptcy risk. ${ }^{2}$ Such effect of bankruptcy may also contribute

\footnotetext{
${ }^{2}$ For instance when cash is so low that the firm inevitably goes bankrupt, marginally increasing the available cash may not help at all. After a certain point, marginally increasing the cash helps the firm reduce the bankruptcy risk; at that point, the returns to cash are increasing. Further increasing the cash available further reduces the chances of bankruptcy, but with decreasing marginal returns.
} 
Figure 1 Shadow prices when $t=0$ as a function of the initial cash position $I_{0}$.

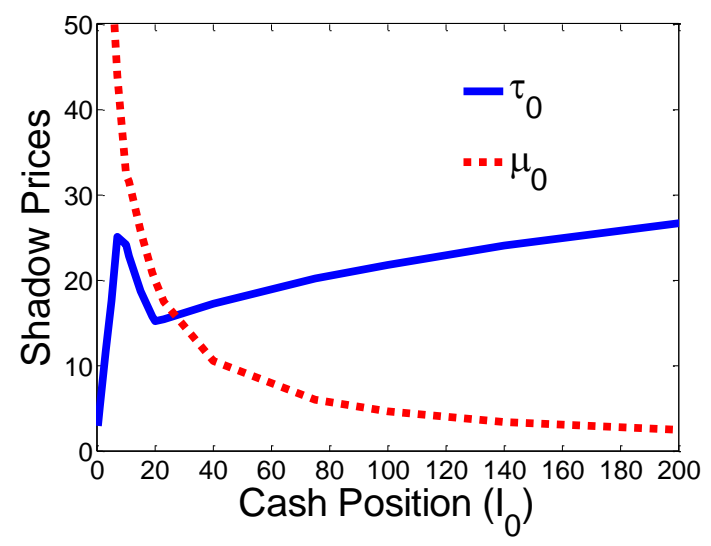

Note. $R(M, T, Z)=1.1 M^{0.9} T^{0.3}+Z, r=0.1, B(M, I, Z)=0.8[M-I]^{+}$if $M \leq 2 I$ and $\infty$ otherwise, $J=20, N=12$, $\phi_{t}\left(Z_{t}, \omega_{t}\right)=Z_{t}+\omega_{t}$, where $\omega_{t} \sim N(0,20), L=0, K=100$.

to the non-monotone behavior of $\tau_{0}$ in the region of low cash as observed in Figure 1. Despite this non-monotone behavior of the shadow prices, Proposition 1 guarantees that there is only one bottleneck shift as $I_{0}$ increases, and that this shift is from money to time.

Figure 2 illustrates a sample path of the shadow prices of money and time. Due to the growth uncertainty, one may observe multiple bottleneck shifts over time. Initially, the key bottleneck is money $\left(\mu_{t}>\tau_{t}\right)$. Although both shadow prices start falling, $\mu_{t}$ falls faster than $\tau_{t}$, eventually making time the bottleneck. But at the end of period 2, a shock in the economy $\left(Z_{t}\right)$ drains the available cash and temporarily resurrects money as the bottleneck, which is then alleviated as the firm's cash position grows. Similar shifts could happen due to learning effects and process improvement when the available time $\left(J_{t}\right)$ is non-stationary, which would provide the entrepreneur with more time as the firm grows. If available time were constant $\left(J_{t}=J\right)$ and the state of the economy such that growth was ensured in every period, the bottleneck would shift only once.

\section{Hiring to Trade Off Money for Time}

When the bottleneck shifts from money to time as the firm grows, it may be attractive to buy more time by hiring an employee. In this section, we first present the model and then characterize the optimal timing of hiring the first employee in terms of a one-step look-ahead policy (OSLA) and then do the same for firing.

\subsection{Model}

In this section, we enhance the growth model presented in (1) by allowing the entrepreneur to hire an employee, who brings $y$ additional units of time and costs a wage $w$. To allow for a difference in productivity between the entrepreneur and the new hire, we convert the employee's time to the time it would take the entrepreneur to do the same tasks, so after hiring, the total available time increases to $J_{t}+y$. The available money decreases to $I_{t}-w$. 
Figure 2 Sample path of shadow prices over time.

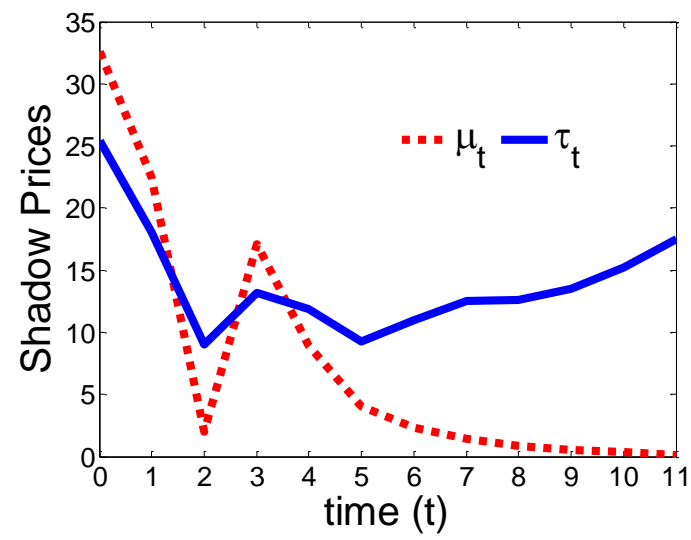

Note. Same parameter values as in Figure 1 with $\left\{Z_{t}\right\}_{t=0}^{11}=\{0,-6.7,-45,-15,-10.5,3.4,-3.2,-21.4,-10.3,9.7,29.8,36\}$ and $I_{0}=10$.

Especially for entrepreneurs, hiring can be costly and time-consuming (Tansky and Heneman 2006). It costs money to advertise the position or use a recruiting agency, and then to provide equipment and training for the new employee. The entrepreneur must also spend time to screen applications (e.g., search on LinkedIn), assess the candidates' fit and values, and train them. We assume the entrepreneur incurs a fixed hiring cost $H_{M} \geq 0$ and hiring time $H_{T} \geq 0$ in the period she hires the employee. The available cash in the hiring period, say $t$, is $I_{t}-w-H_{M}$ and the available time is $J_{t}+y-H_{T}$. Firing an employee may also cost money and time, denoted $F_{M}$ and $F_{T}$. Assuming that firing takes place immediately, the available cash in the firing period, say $t$, is $I_{t}-F_{M}$ and the available time is $J_{t}-F_{T}$. Effectively, these hiring/firing costs/times act as hiring frictions, consistent with the irreversible nature of capacity investments (Dixit and Pindyck 1994).

In reality, hiring presents additional challenges, related to fit with the firm's culture or uncertainty about the employee's capabilities (Hess 2012). We do not consider such factors explicitly, as they are tangential to the time-money trade-off explored here, and for lower-level positions (e.g., office manager), which tend to be hired first (Hess 2012, p. 72), they tend to be less relevant. The greater these challenges, the greater our $H_{M}$ and $H_{T}$ will be.

Let $E_{t} \in\{0,1\}$, where $E_{t}=1$ when an employee has been hired prior to $t$ and $E_{t}=0$ otherwise. Let $V_{t}\left(E_{t}, I_{t}, Z_{t}\right)$ denote the firm's expected cash value in period $N$ when the number of employees at the beginning of period $t$ is $E_{t}$, the available cash is $I_{t}$, and the state of the economy is $Z_{t}$. Incorporating hiring and firing in the growth model (1) leads to:

$$
\begin{aligned}
V_{t}\left(0, I_{t}, Z_{t}\right)= & \max _{E_{t} \in\{0,1\}} \max _{M_{t}, T_{t} \leq J_{t}+\left(y-H_{T}\right) E_{t}} \delta \mathbb{E}_{\omega_{t}}\left[V _ { t + 1 } \left(E_{t},(1+r)\left(I_{t}-\left(w+H_{M}\right) E_{t}\right)\right.\right. \\
& \left.\left.+\Pi\left(M_{t}, T_{t} \mid I_{t}-\left(w+H_{M}\right) E_{t}, Z_{t}\right), \phi_{t}\left(Z_{t}, \omega_{t}\right)\right)\right] \quad \text { if } I_{t} \geq L, t=0, \ldots, N-1 \\
V_{t}\left(1, I_{t}, Z_{t}\right)= & \max _{E_{t} \in\{0,1\}} \max _{M_{t}, T_{t} \leq J_{t}+y E_{t}-F_{T}\left(1-E_{t}\right)} \delta \mathbb{E}_{\omega_{t}}\left[V _ { t + 1 } \left(E_{t},(1+r)\left(I_{t}-w E_{t}-F_{M}\left(1-E_{t}\right)\right)\right.\right.
\end{aligned}
$$




$$
\begin{array}{cl}
\left.\left.\quad+\Pi\left(M_{t}, T_{t} \mid I_{t}-w E_{t}-F_{M}\left(1-E_{t}\right), Z_{t}\right), \phi_{t}\left(Z_{t}, \omega_{t}\right)\right)\right] & \text { if } I_{t} \geq L, t=0, \ldots, N-1 \\
V_{N}\left(E_{N}, I_{N}, Z_{N}\right)=I_{N} & \text { if } I_{N} \geq L, \\
V_{t}\left(E_{t}, I_{t}, Z_{t}\right)=-K & \text { if } I_{t}<L .
\end{array}
$$

Similar to Lemma 1, the optimal time and money investment policy turns out to be myopic. To reflect the different hiring and firing frictions, we denote with $f\left(I_{t}, J_{t}, Z_{t}\right), g_{H}\left(I_{t}, J_{t}, Z_{t}\right)$, $g_{F}\left(I_{t}, J_{t}, Z_{t}\right)$, and $h\left(I_{t}, J_{t}, Z_{t}\right)$ the transition functions of the available cash $\left(I_{t}\right)$ when no employee has been hired $\left(E_{t}=0\right)$, when an employee has just been hired $\left(E_{t-1}=0, E_{t}=1\right)$, just been fired $\left(E_{t-1}=1, E_{t}=0\right)$, or hired in a previous period $\left(E_{t-1}=1\right)$, respectively defined as follows:

$$
\begin{aligned}
f\left(I_{t}, J_{t}, Z_{t}\right) & \equiv(1+r) I_{t}+\Pi^{*}\left(I_{t}, J_{t}, Z_{t}\right), \\
g_{H}\left(I_{t}, J_{t}, Z_{t}\right) & \equiv(1+r)\left(I_{t}-w-H_{M}\right)+\Pi^{*}\left(I_{t}-w-H_{M}, J_{t}+y-H_{T}, Z_{t}\right), \\
g_{F}\left(I_{t}, J_{t}, Z_{t}\right) & \equiv(1+r)\left(I_{t}-F_{M}\right)+\Pi^{*}\left(I_{t}-F_{M}, J_{t}-F_{T}, Z_{t}\right), \text { and } \\
h\left(I_{t}, J_{t}, Z_{t}\right) & \equiv(1+r)\left(I_{t}-w\right)+\Pi^{*}\left(I_{t}-w, J_{t}+y, Z_{t}\right) .
\end{aligned}
$$

Using these notations, the dynamic programming formulation (4) simplifies to:

$$
\begin{aligned}
& V_{t}\left(0, I_{t}, Z_{t}\right)=\delta \max \left\{\mathbb{E}_{\omega_{t}}\left[V_{t+1}\left(0, f\left(I_{t}, J_{t}, Z_{t}\right), \phi_{t}\left(Z_{t}, \omega_{t}\right)\right)\right],\right. \\
& \left.\mathbb{E}_{\omega_{t}}\left[V_{t+1}\left(1, g_{H}\left(I_{t}, J_{t}, Z_{t}\right), \phi_{t}\left(Z_{t}, \omega_{t}\right)\right)\right]\right\} \quad \text { if } I_{t} \geq L, t=0, \ldots, N-1 \\
& V_{t}\left(1, I_{t}, Z_{t}\right)=\delta \max \left\{\mathbb{E}_{\omega_{t}}\left[V_{t+1}\left(1, h\left(I_{t}, J_{t}, Z_{t}\right), \phi_{t}\left(Z_{t}, \omega_{t}\right)\right)\right],\right. \\
& V_{N}\left(E_{N}, I_{N}, Z_{N}\right)=I_{N} \\
& \left.\mathbb{E}_{\omega_{t}}\left[V_{t+1}\left(0, g_{F}\left(I_{t}, J_{t}, Z_{t}\right), \phi_{t}\left(Z_{t}, \omega_{t}\right)\right)\right]\right\} \\
& V_{t}\left(E_{t}, I_{t}, Z_{t}\right)=-K \\
& \text { if } I_{t} \geq L, t=0, \ldots, N-1 \\
& \text { if } I_{N} \geq L \text {, } \\
& \text { if } I_{t}<L \text {. }
\end{aligned}
$$

In the next two sections, we characterize the optimal timing of hiring and firing of an employee. Our analytical treatment of hiring and firing is separate, but our numerical experiments in $\S 5$ consider both simultaneously.

\subsection{Optimal Timing of Hiring}

We first characterize the optimal timing of hiring. We focus primarily on a one-step look-ahead $(O S L A)$ policy. We first characterize its structure, then study its sensitivity to the problem parameters, and finally show that it is optimal in case of deterministic growth. We show numerically in $\S 5$ that the $O S L A$ policy performs very well even in case of non-monotone, stochastic growth. The practical implication of this result is that entrepreneurs do not need complete foresight, but could instead base their hiring decisions on their forecasts of the immediate future.

4.2.1. One-Step Look-Ahead Policy. If the current period is $t$, the $O S L A$ policy aims at maximizing the cash position at the end of the following period, i.e., $I_{t+2}$, ignoring everything that may occur from period $t+2$ onwards. Accordingly, the $O S L A$ policy recommends to hire in period $t$ if and only if that generates more cash by the end of period $t+1$ than hiring in period $t+1$. In 
principle, the entrepreneur could also decide not to hire before $t+2$. The $O S L A$ policy excludes that option as it would lead to conservative hiring given that the benefits are reaped after the $O S L A$ horizon. (All our analytical results do hold if the OSLA policy allows for that option.)

We first need an assumption on the hiring costs and times: the higher the cash position at the beginning of a period, the more attractive it becomes to hire to maximize the next-period starting cash position $I_{t+1}$. For example, this always holds when the hiring time is no greater than the resulting time gain, i.e., when $H_{T} \leq y$, as shown in Lemma A-4 in the appendix.

Assumption 1. $\left(H_{M}, H_{T}\right)$ are such that $g_{H}(I, J, Z)-f(I, J, Z)$ is increasing in $I$.

This assumption allows one to characterize the timing of hiring in terms of the firm's cash position. The next lemma shows that the $O S L A$ hiring policy in each period $t$ can be characterized in terms of a single cash threshold.

Lemma 2 (OSLA Hiring Policy). Define

$$
\begin{aligned}
I_{H, t}^{O S L A}=\min \{I \mid & \mathbb{E}_{\omega_{t}}\left[h\left(g_{H}\left(I, J_{t}, Z_{t}\right), J_{t+1}, \phi_{t}\left(Z_{t}, \omega_{t}\right)\right)\right] \geq \mathbb{E}_{\omega_{t}}\left[g_{H}\left(f\left(I, J_{t}, Z_{t}\right), J_{t+1}, \phi_{t}\left(Z_{t}, \omega_{t}\right)\right)\right], \\
& \text { and } \left.g_{H}\left(I, J_{t}, Z_{t}\right) \geq L\right\} .
\end{aligned}
$$

The OSLA policy recommends to hire in period $t$ if and only if $I_{t}>I_{H, t}^{O S L A}$.

An increase in $I_{H, t}^{O S L A}$ corresponds to a delay in the timing of hiring as the firm must accumulate a higher cash level. Hiring is attractive only when the firm's cash position is large enough. As one CEO of a small firm put it, "we did not hire unless we had cash flow in house to pay their salary and benefits for three to four months" (Hess 2012, p. 82).

4.2.2. Sensitivity of $O S L A$ Hiring Policy. In this section, we characterize the sensitivity of the $O S L A$ hiring cash threshold to available time $\left(J_{t}\right)$, state of the economy $\left(Z_{t}\right)$, and hiring times and costs $\left(H_{T}\right.$ and $\left.H_{M}\right)$. Due to the complementarity of time and money and their substitutability through hiring, the sensitivity analysis is in general intricate. We first consider the effect of time available on the timing of hiring. The effect of $J_{t}$ on the timing of hiring is in general ambiguous. On the one hand, more time available today increases the return on monetary investments in the current period, which favors not incurring the hiring cost and wage in the current period. On the other hand, more time available today creates more cash in the next period, which increases the return on time investments in the next period, and therefore favors not incurring the hiring time then. When hiring is frictionless (i.e., $H_{T}=H_{M}=0$ ), only the first effect is present, provided that bankruptcy is not a threat (e.g., $L=-\infty$ ), pushing towards delaying hiring. On the other hand, the effect of $J_{t+1}$ on the timing of hiring is unequivocal: if the entrepreneur has more time available in period $t+1$, she is less inclined to hire in period $t$. 
Proposition 2 (Sensitivity to Time Available). Suppose that Assumption 1 holds. Then $I_{H, t}^{O S L A}$ is increasing in $J_{t+1}$. If $H_{T}=H_{M}=0$ and $L=-\infty, I_{H, t}^{O S L A}$ is also increasing in $J_{t}$.

We next characterize the sensitivity of the hiring timing with respect to the state of the economy, which is again non-monotone. If the entrepreneur hires in period $t$, she will have more time but possibly less cash available in period $t+1$ than if she hired in period $t+1$. Depending on whether the state of the economy has a greater effect on the returns on cash or time, a higher state may thus expedite or delay hiring. In order to obtain a finer characterization, we assume that the current state of the economy does not affect the current period's time and money investment decisions. Similar additive representations of uncertainty have been adopted by Li (1988), Radner and Shepp (1996), and Caldentey and Haugh (2006). Berger and Udell (1998) note that loan interest rates for small firms are "sticky," i.e., are typically not adjusted when the interest rates change; for instance, Evans and Jovanovic (1989) use $B(M, I, Z)=b[M-I]$ and Kouvelis and Zhao (2011) use $B(M, I, Z)=b(M)[M-I]^{+}$, both independent of $Z$. Effectively, this assumption formalizes the notion that only money $\left(M_{t}\right)$ and time $\left(T_{t}\right)$ can be the bottlenecks of the firm in the short term.

Assumption 2. $R(M, T, Z)-B(M, I, Z)$ is separable in $(M, T, I)$ and $Z$.

Under this assumption, we find that the higher the current state of the economy, the more likely one should hire in the current period: with a higher state, more cash is generated today, so the marginal returns on time in period $t+1$ will be higher, favoring hiring in the current period. ${ }^{3}$

Proposition 3 (Sensitivity to State of the Economy). Suppose Assumptions 1 and 2 hold. Then $I_{H, t}^{O S L A}$ is decreasing in $Z_{t}$ and is independent of $Z_{t+1}$.

The sensitivity of the timing of hiring with respect to the hiring cost and time again displays nonmonotone effects. The second part of the next proposition characterizes a special case in which such a non-monotone effect arises. This case requires two conditions, which are satisfied, in particular, when $R(M, T, Z)=M^{\alpha} T^{\beta}+Z$ for some $\alpha, \beta>0, \alpha+\beta<1$ and when $B(M, I, Z)=b[M-I]^{+}$.

Proposition 4 (Sensitivity to Hiring Time and Hiring Cost). Suppose Assumption 1 holds. Then:

(i) $I_{H, t}^{O S L A}$ is increasing in $H_{M}$;

(ii) If Assumption 2 holds and $\frac{\partial^{2} \Pi^{*}(I, J, Z)}{\partial J^{2}} / \frac{\partial \Pi^{*}(I, J, Z)}{\partial J}$ is increasing in $I$, then $I_{H, t}^{O S L A}$ is unimodal, decreasing-increasing in $H_{T}$.

\footnotetext{
${ }^{3}$ The result regarding the monotone impact of $Z_{t}$ on $I_{H, t}^{O S L A}$ can be strengthened if, instead of Assumption 2, $R(M, T, Z)-B(M, I, Z)$ were assumed to be supermodular in $(M, T, I,-Z)$ and $H_{T} \geq y$. In that case, one would be more willing to incur the resource drain associated with the hiring cost and hiring time when the state of the economy is high, further expediting hiring in period $t$.
} 
Figure 3 Sensitivity of $O S L A$ hiring cash threshold to hiring time.

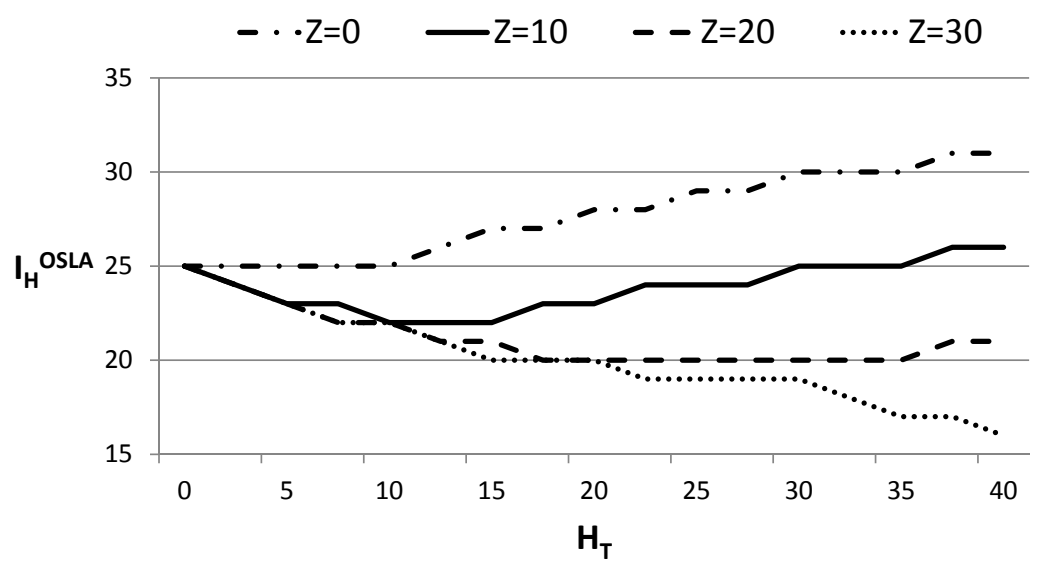

Note. $R(M, T, Z)=0.4 M^{0.7} T^{0.7}+Z$, where $Z_{t+1}=Z_{t}+\omega_{t}$, in which $\omega_{t}$ is equal to 5 , -5 , or 0 respectively with probability $0.375,0.375,0.25$. Moreover, $B(M, I, Z)=(0.2 / 12)[M-I]^{+}$if $M<2 I$, and $\infty$ otherwise; $r=0.025 / 12, J=$ $30, I_{0}=20$.

An increase in either the hiring cost $\left(H_{M}\right)$ or time $\left(H_{T}\right)$ lowers the revenue in the hiring period and therefore slows down future growth. If $H_{M}$ increases, delaying hiring is optimal as it postpones the resource drain to a period where money is less valuable, as shown in Proposition 4(i). By contrast, the effect of an increase in $H_{T}$ need not be monotone, as shown in Proposition 4(ii). Two opposing effects are at play. An increase in $H_{T}$ favors delaying hiring in order to postpone incurring the increased (time) cost of hiring. Conversely, the opportunity cost of time increases over time, so the entrepreneur would prefer to hire earlier in order to incur the increased hiring time $H_{T}$ earlier when time is cheaper. This effect is illustrated in Figure 3. The OSLA hiring cash threshold $I_{H, t}^{O S L A}$ can be increasing in $H_{T}$ (when $Z=0$ ), decreasing in $H_{T}$ (when $Z=30$ ), or decreasing-increasing in $H_{T}$ (when $Z=10$ and $Z=20$ ).

This difference in the effect of hiring cost and time highlights the importance of differentiating between money and time in early-stage growth-oriented entrepreneurial firms. In classical staffing models, fixed setup times are often implicitly converted to fixed setup costs. For example, Gans and Zhou (2002, p. 994) suggest that the fixed hiring cost "typically includes advertising for, interviewing, and testing of job applicants when appropriate. It may also include one-time training costs that are independent of wages." This is appropriate in larger firms, as studied by Gans and Zhou (2002) and others, but not in our context: if the hiring time were treated as hiring cost, then one would always delay hiring in response to an increase in hiring time, potentially conflicting with our prescription.

4.2.3. Optimality of $O S L A$ Hiring Policy. We next show that the $O S L A$ hiring policy, despite its simplicity, is optimal when the firm grows deterministically, as in staffing planning 
models (going back to Holt et al. 1960). In $\S 5$, we show numerically that it performs very well even when growth is not guaranteed.

The first half of Proposition 5 below shows that in a deterministic setting it is never optimal to hire if the firm's cash position falls below $I_{H, t}^{O S L A}$, establishing necessity of the OSLA hiring threshold condition. The second half shows sufficiency when three assumptions hold: increasing state of economy, which is common in the entrepreneurship literature (Babich and Sobel 2004) and the capacity expansion literature (e.g., Luss 1982, Angelus and Porteus 2002); profitability (i.e., $\left.f\left(I, J, Z_{t}\right) \geq I\right)$; and constant available time $\left(J_{t+k}=J_{t}\right.$ for all $\left.k\right)$.

Proposition 5 (Optimality of OSLA Hiring Policy). Suppose that Assumptions 1 and 2 hold true and that $\left|\Omega_{t+k}\right|=1$ for all $k \geq 0$.

If it is optimal to hire in period $t$, then $I_{t}>I_{H, t}^{O S L A}$.

Suppose also that (i) $Z_{t+k} \leq Z_{t+k+1}$ for all $k \geq 0$, (ii) $f\left(I, J, Z_{t}\right) \geq I$, and (iii) $J_{t+k}=J_{t+k+1}$ for all $k \geq 0$. Then it is optimal to hire in period $t$ if and only if $I_{t}>I_{H, t}^{O S L A}$.

The rationale behind this result is as follows: By Propositions 2 and 3, under growing states of the economy $\left(Z_{t}\right)$ and with constant time available for the entrepreneur $\left(J_{t}\right)$, the $O S L A$ hiring thresholds are decreasing over time. On the other hand under the specified growth conditions, the firm's cash position is increasing over time. As a result, the firm's cash position will cross the hiring threshold only once; accordingly, if the $O S L A$ policy prescribes to hire in period $t$, it will also do so in all subsequent periods. Effectively, the hiring set is absorbing (Bertsekas 2000).

\subsection{Optimal Timing of Firing}

We next consider the timing of firing, ignoring the possibility of re-hiring the employee later. Despite treating hiring and firing separately, we show in $\S 5$ that our $O S L A$ hiring and firing policy performs well in general. By and large, the results mirror those obtained before, thus deepening the connection between hiring/firing and capacity expansion/contraction. We first characterize the $O S L A$ firing policy, then study its sensitivity to the model parameters, and finally establish that it is optimal under certain conditions.

Under the $O S L A$ firing policy, the employee is fired in period $t$ if this increases $I_{t+2}$ more than firing him in period $t+1$. We assume, in the same spirit as Assumption 1, that firing does not take any time $\left(F_{T}=0\right)$ and that the firing cost is not too large (for instance, $F_{M} \leq w$, as shown in Lemma A-9). These assumptions are sufficient, and not necessary, for the following results to hold. Based on our interaction with entrepreneurs, firing often does not entail significant time investment and the only cost is often a severance package, usually no more than one month of salary. Moreover in $\S 5$, we numerically observe that, despite these limited frictions, firing typically only occurs when the firm is on the verge of going bankrupt and offers only marginal relief. 
Assumption 3. $F_{T}=0$ and $F_{M}$ is such that $g_{F}(I, J, Z)-h(I, J, Z)$ is decreasing in $I$.

Under this assumption, the optimal policy can be characterized by two cash thresholds: the entrepreneur should fire the employee if her cash position is sufficiently low that keeping him one more period would not be economical, but not so low that the firing cost will cause bankruptcy.

Lemma 3 (OSLA Firing Policy). Suppose that Assumption 3 holds. Define

$$
\bar{I}_{F, t}^{O S L A}=\max \left\{I \mid g_{F}\left(I, J_{t}, Z_{t}\right) \geq h\left(I, J_{t}, Z_{t}\right)-F_{M}\right\} \text { and } \underline{I}_{F, t}^{O S L A}=\min \left\{I \mid g_{H}\left(I, J_{t}, Z_{t}\right) \geq L\right\}
$$

The OSLA policy recommends to fire in period $t$ if and only if $\underline{I}_{F, t}^{O S L A} \leq I_{t} \leq \bar{I}_{F, t}^{O S L A}$.

The next result mirrors Proposition 5 by demonstrating the optimality of the $O S L A$ firing policy when the future is deterministic, as often assumed in staffing models (Holt et al. 1960). As before, we first establish necessity of the $O S L A$ firing cash thresholds, and then, under additional assumptions, show that they are also sufficient. Contrary to hiring, the optimality of the OSLA firing policy is established in case of decline, and not growth. (For sensitivity results, see Proposition A-1 in Appendix.)

Proposition 6 (Optimality of OSLA Firing Policy). Suppose that Assumption 3 holds and that $\left|\Omega_{t+k}\right|=1$ for all $k \geq 0$.

If it is optimal to fire in period t, then $\underline{I}_{F, t}^{O S L A} \leq I_{t} \leq \bar{I}_{F, t}^{O S L A}$.

Suppose also that (i) either $J_{t+k}=J_{t+k+1}$ for all $k \geq 0$ or $J_{t+k} \leq J_{t+k+1}$ for all $k \geq 0$ and $F_{M} \geq w$, (ii) Assumption 2 holds, and (iii) $h\left(I, J_{t+k}, Z_{t+k}\right) \leq I$ for all $k \geq 0$. Then it is optimal to fire in period $t$ if and only if $\underline{I}_{F, t}^{O S L A} \leq I_{t} \leq \bar{I}_{F, t}^{O S L A}$.

If $I_{H, t}^{O S L A} \geq \bar{I}_{F, t}^{O S L A}$, the $O S L A$ hiring-firing policy is similar to the classical "Invest-Stay PutDisinvest" policy of capacity expansion (Van Mieghem 2003), under which it is optimal to hire at high cash levels, keep that employee (stay put) at intermediate levels, and fire that employee at lower (but not too low) cash levels. (When the cash level is very low, i.e., below $\underline{I}_{F, t}^{O S L A}$, it may be optimal not to fire the employee if incurring the firing cost would precipitate the firm into bankruptcy.) This result helps further draw the parallel between hiring and capacity expansion.

\section{Numerical Analysis}

In this section, we show numerically that the $O S L A$ policy is near-optimal and demonstrate its robustness. We first describe the parameter values used in our experiments, then compare the $O S L A$ policy with the optimal policy, and finally discuss its robustness. 


\subsection{Setup and Illustrative Examples}

As a base case, we consider an entrepreneur who seeks to maximize the firm's cash position after $N=12$ months, starting with $I_{0}=\$ 20,000$ and working $J=30$ days per month. Money can be borrowed at an annual rate $b=20 \%$ with a borrowing limit of $\kappa=100 \%$ of current cash level, similar to Buzacott and Zhang (2004), so $B(M, I, Z)=b[M-I]^{+}$if $M \leq(1+\kappa) I$ and $B(M, I, Z)=\infty$ otherwise. Excess money can be invested at an annual rate of $r=2.5 \%$, and $\delta=1 /(1+r)$. The entrepreneur is bankrupt when her cash position falls below $L=0$, which triggers bankruptcy costs of $K=\$ 100,000$, which could roughly represent one year of lost salary while looking for a new job.

We consider a Cobb-Douglas revenue function, similar to Lévesque and MacCrimmon (1997), and additive shocks, so $R(M, T, Z)=k M^{\alpha} T^{\beta}+Z$ with $\alpha<1$. Similar to Babich and Sobel (2004), we assume that the state of the economy follows a martingale, i.e., $Z_{t+1}=\phi\left(Z_{t}, \omega_{t}\right)=Z_{t}+\omega_{t}$, in which $\omega_{t}$ is equal to $\$ 5,000,-\$ 5,000$, or $\$ 0$ respectively with probability $p, q$, and $1-p-q$. In our base case, we set $Z_{0}=\$ 0 .{ }^{4}$ The entrepreneur's range of uncertainty about the economy increases with her time horizon, but she may lose or gain up to $25 \%$ of her initial endowment $\left(I_{0}\right)$ even in the first period. In our base case, we set $p=0.375$ and $q=0.375$. We also consider an optimistic scenario, i.e., $p=0.5$ and $q=0.25$, and a pessimistic one, i.e., $p=0.25$ and $q=0.5$.

We assume that, if the entrepreneur were to invest all her initial endowment of time and money, she would face, in expectation, a return of $5 \%$ in the first month, i.e., $R\left(I_{0}, J, Z_{0}\right) /\left[(1+r) I_{0}\right]=1.05$, which roughly translates into a $180 \%$ annual growth rate, not atypical for growing entrepreneurs. We accordingly set $k=1.05(1+r)(20)^{1-\alpha} J^{-\beta}$. In line with Proposition 1 , we assume that money is initially the bottleneck: the money the entrepreneur would like to invest in the business (the solution to the first-order condition $\partial R(M, J, Z) / \partial M-(1+r)=0)$ is greater than her initial cash endowment $\left(I_{0}=\$ 20,000\right)$. Mathematically, we require that $\left(\alpha J^{\beta} k /(1+r)\right)^{\frac{1}{1-\alpha}} \geq \$ 20,000$, i.e., $\alpha \geq 1 / 1.05 \approx 0.95$. In our base case, we assume $\alpha=0.99$ to ensure that cash will be the bottleneck for at least a few periods. We consider three values for the elasticity of time: $\beta=0.7, \beta=0.3$, and $\beta=3$. Figure 4 depicts a few representative sample paths of the cash position under this base case, when $\beta=0.7$, assuming no hiring. The expected initial $5 \%$-growth rate does not always materialize and certainly does not guarantee the firm's future growth.

Now assume the entrepreneur can hire an employee, costing $w=\$ 6,000$ per month and giving the entrepreneur an extra $y=15$ days of time per month to grow the business. Since recruiting agencies typically collect one or two months of salary, we set $H_{M}=\$ 12,000$. We assume hiring takes considerable time, and set $H_{T}=30$ days (resulting in available time of 15 days during the hiring period). By contrast, firing takes no time and costs one month's severance, so $F_{T}=0$ and

${ }^{4}$ With different starting points $Z_{0}$, we set $\phi\left(Z_{t}, \omega_{t}\right)=\min \left\{(N+1) 5,000, \max \left\{-(N+1) 5,000, Z_{t}+\omega_{t}\right\}\right\}$ and set an upper bound of $\$ 1,000,000$ on $I_{t}$ to limit the state space while solving the dynamic program. 
Figure 4 Sample paths of cash and state of the economy with no hiring.
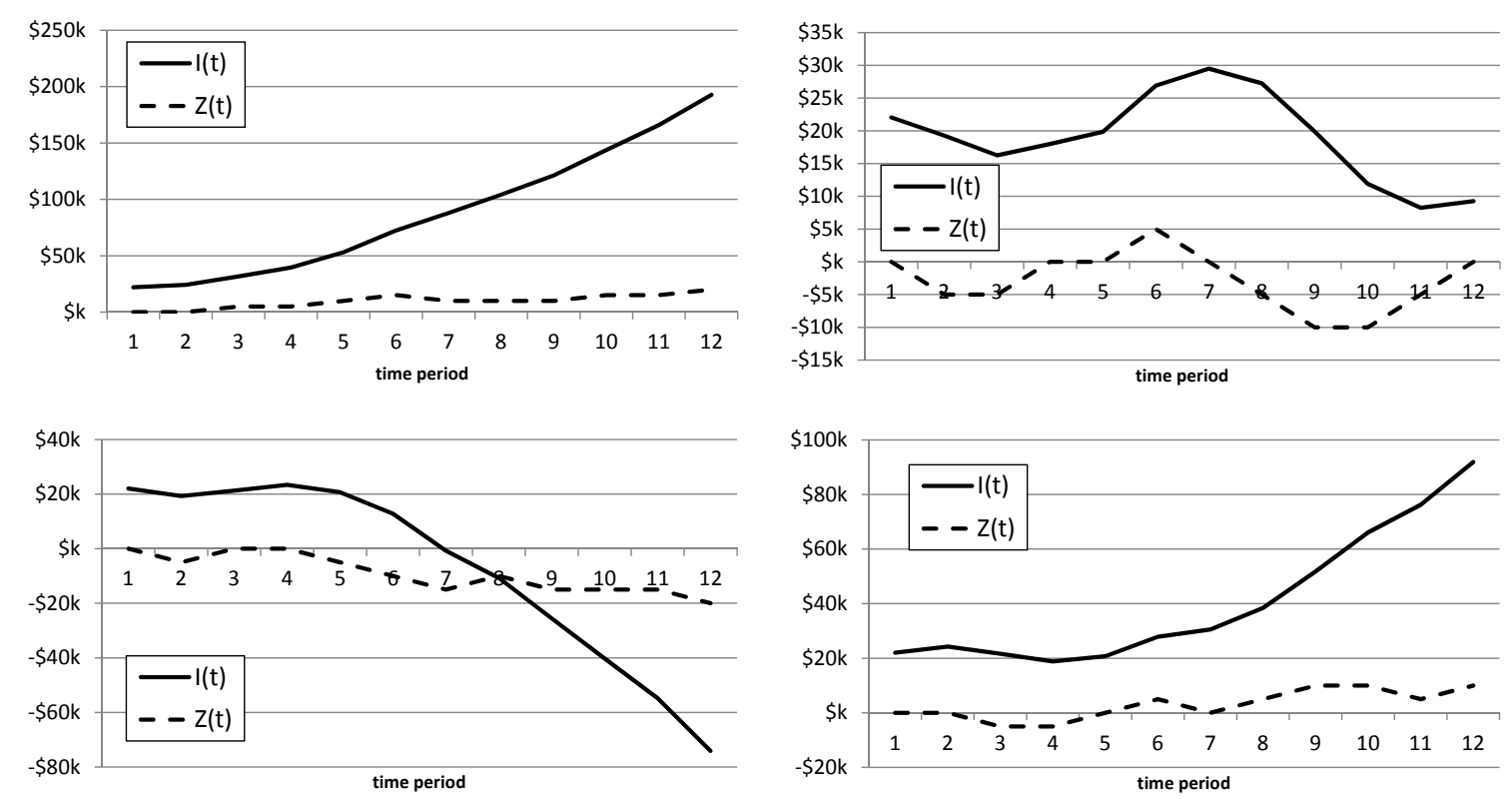

Figure 5 Distribution of final discounted cash $\left(\delta^{N} I_{N}\right)$ without hiring and hiring via $O S L A$ policy.

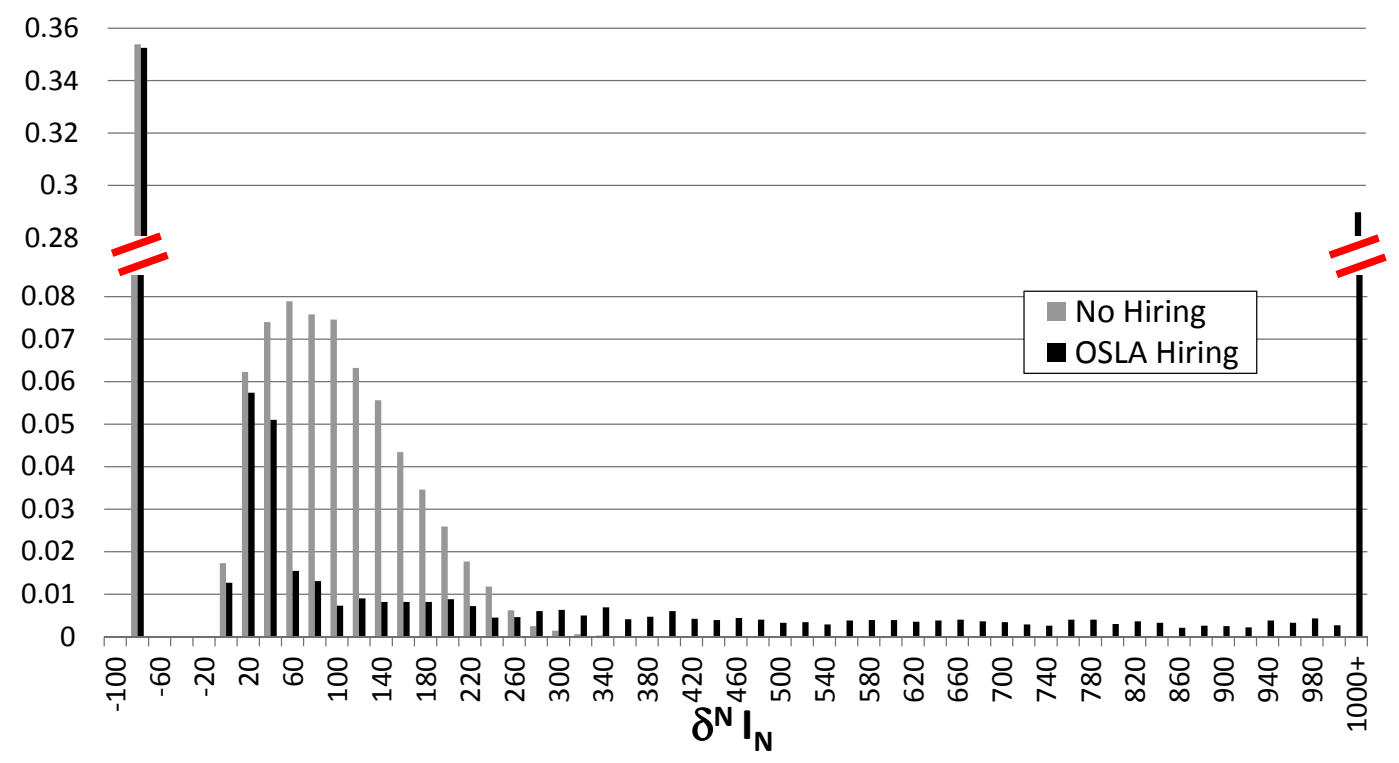

$F_{M}=\$ 6,000$. Note that, even though the derivation of the $O S L A$ policy considers hiring and firing separately, we consider them jointly here; in particular, the optimal policy to which we benchmark the $O S L A$ policy could potentially recommend several cycles of hiring and firing.

Is hiring valuable in our setting? Figure 5 plots the histogram of the discounted final cash $\left(\delta^{N} I_{N}\right)$ without hiring and with the $O S L A$ hiring policy for $p=0.375$ and $q=0.375$ averaged over 10,000 scenarios. The $O S L A$ policy first-order stochastically dominates the no-hiring policy. Hiring via the OSLA policy has limited influence on the bankruptcy probability (35.3\% vs. $35.4 \%$ for no- 
Figure 6 Distribution of $O S L A$ hiring times for different levels of economic drifts.

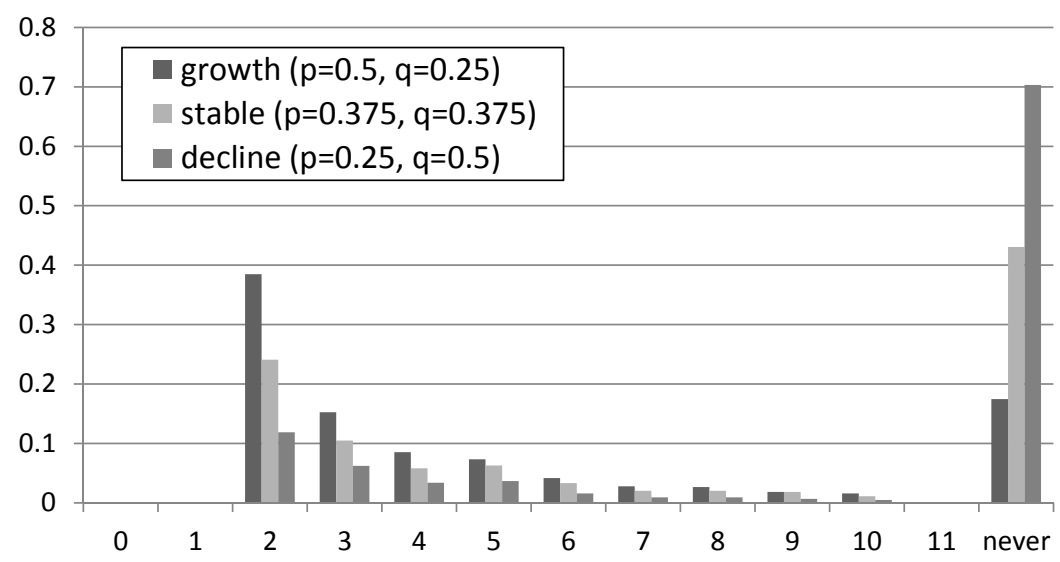

hiring), but significantly improves the firms chance of higher growth. Without hiring the firm does not exceed $\delta^{N} I_{N}=350$, but with $O S L A$-hiring there is a $28 \%$ probability of the firm reaching $\delta^{N} I_{N}=1000$ or higher.

Figure 6 depicts a histogram of the OSLA hiring times in our base case $(\beta=0.7)$ under growing, stable, and declining state of the economy, averaged over 10,000 scenarios. Conditional on hiring taking place, the median hiring time is period 4 in all three cases, and the mean hiring time is between 4.5 and 4.7 . The probability of hiring is larger if the state of the economy $\left(Z_{t}\right)$ has a positive rather than negative drift, consistent with Proposition 3.

\subsection{Performance of $O S L A$ Policy}

Tables 1-3 display, for $\beta=0.7, \beta=0.3$, and $\beta=3$, the expected cash position in period $N$ (in $\$ 1,000$ 's), evaluated in period 0 , using the optimal hiring policy $\left(V_{0}^{O P T}\right)$ and using the $O S L A$ hiring policy $\left(V_{0}^{O S L A}\right)$ for various starting cash positions and states of the economy. The optimality gap is defined as $\Delta=\left(V_{0}^{O P T}-V_{0}^{O S L A}\right) /\left|V_{0}^{O P T}\right|$. Overall, the tables show that the $O S L A$ policy performs very well, typically within a few percent from the optimal policy. In particular, in all reported instances, the optimality loss is never larger than $\$ 3,000$. The $O S L A$ policy performs well because in our setting, (i) time and money investments are expected to generate growth and (ii) cash accumulation accelerates growth due to the bootstrapping nature. In other settings (e.g., with limited growth opportunities, negative profitability, or no ability to bootstrap), the OSLA policy may not work well, but these settings would fundamentally differ from our growth context. Apart from the obvious computational benefits, the good performance of the OSLA policy implies that entrepreneurs facing growth opportunities may limit their horizon to one period and still do quite well.

How sensitive is hiring to the prospect of being able to fire? In our growth setting, it turns out that firing has very little impact on the performance of both the optimal and the OSLA policy. 


\begin{tabular}{|c|c||r|r|r|r|r|r|r|r|r|r|}
\hline & \multicolumn{9}{|c||}{$p=0.5, q=0.25$} & \multicolumn{3}{c||}{$p=0.375, q=0.375$} & \multicolumn{3}{c|}{$p=0.25, q=0.5$} \\
\hline$I_{0}$ & $Z_{0}$ & $V_{0}^{O P T}$ & $V_{0}^{O S L A}$ & $\Delta$ & $V_{0}^{O P T}$ & $V_{0}^{O S L A}$ & $\Delta$ & $V_{0}^{O P T}$ & $V_{0}^{O S L A}$ & $\Delta$ \\
\hline 20 & 0 & 607 & 606 & $0.1 \%$ & 346 & 345 & $0.2 \%$ & 114 & 114 & $0.4 \%$ \\
20 & -10 & -18 & -19 & $2.9 \%$ & -75 & -75 & $0.3 \%$ & -95 & -95 & $0.1 \%$ \\
20 & 10 & 977 & 977 & $0.0 \%$ & 974 & 974 & $0.0 \%$ & 962 & 962 & $0.0 \%$ \\
10 & 0 & 472 & 472 & $0.2 \%$ & 215 & 215 & $0.4 \%$ & 26 & 25 & $2.2 \%$ \\
10 & -10 & -100 & -100 & $0.0 \%$ & -100 & -100 & $0.0 \%$ & -100 & -100 & $0.0 \%$ \\
10 & 10 & 945 & 945 & $0.0 \%$ & 867 & 866 & $0.0 \%$ & 715 & 715 & $0.0 \%$ \\
30 & 0 & 755 & 754 & $0.1 \%$ & 546 & 545 & $0.1 \%$ & 312 & 312 & $0.1 \%$ \\
30 & -10 & 55 & 54 & $1.7 \%$ & -48 & -48 & $0.9 \%$ & -89 & -89 & $0.1 \%$ \\
30 & 10 & 977 & 977 & $0.0 \%$ & 977 & 977 & $0.0 \%$ & 977 & 977 & $0.0 \%$ \\
\hline
\end{tabular}

Table 1 Performance of OSLA hiring policy when $\beta=0.7$

\begin{tabular}{|l|c||r|r|r||r|r|r||r|r|r|}
\hline & \multicolumn{1}{|c||}{} & \multicolumn{2}{c||}{$p=0.5, q=0.25$} & \multicolumn{2}{c||}{$p=0.375, q=0.375$} & \multicolumn{3}{c|}{$p=0.25, q=0.5$} \\
\hline$I_{0}$ & $Z_{0}$ & $V_{0}^{O P T}$ & $V_{0}^{O S L A}$ & $\Delta$ & $V_{0}^{O P T}$ & $V_{0}^{O S L A}$ & $\Delta$ & $V_{0}^{O P T}$ & $V_{0}^{O S L A}$ & $\Delta$ \\
\hline 20 & 0 & 208 & 206 & $0.8 \%$ & 70 & 68 & $2.6 \%$ & -31 & -32 & $4.6 \%$ \\
20 & -10 & -53 & -54 & $2.3 \%$ & -84 & -84 & $0.6 \%$ & -96 & -96 & $0.1 \%$ \\
20 & 10 & 687 & 687 & $0.0 \%$ & 497 & 496 & $0.1 \%$ & 295 & 293 & $0.6 \%$ \\
10 & 0 & 151 & 149 & $1.3 \%$ & 31 & 29 & $5.5 \%$ & -50 & -51 & $2.0 \%$ \\
10 & -10 & -100 & -100 & $0.0 \%$ & -100 & -100 & $0.0 \%$ & -100 & -100 & $0.0 \%$ \\
10 & 10 & 589 & 589 & $0.0 \%$ & 395 & 394 & $0.2 \%$ & 206 & 204 & $1.0 \%$ \\
30 & 0 & 276 & 274 & $0.5 \%$ & 117 & 115 & $1.5 \%$ & -4 & -6 & $38.4 \%$ \\
30 & -10 & -21 & -23 & $8.9 \%$ & -71 & -72 & $1.1 \%$ & -93 & -93 & $0.2 \%$ \\
30 & 10 & 787 & 787 & $0.0 \%$ & 618 & 618 & $0.0 \%$ & 419 & 419 & $0.0 \%$ \\
\hline
\end{tabular}

Table 2 Performance of OSLA hiring policy when $\beta=0.3$

\begin{tabular}{|c|c||r|r|r|r|r|r|r|r|r|}
\hline & \multicolumn{4}{|c|}{} & \multicolumn{2}{c|}{$p=0.5, q=0.25$} & \multicolumn{3}{c||}{$p=0.375, q=0.375$} & \multicolumn{3}{c|}{$p=0.25, q=0.5$} \\
\hline$I_{0}$ & $Z_{0}$ & $V_{0}^{O P T}$ & $V_{0}^{\text {OSLA }}$ & $\Delta$ & $V_{0}^{\text {OPT }}$ & $V_{0}^{\text {OSLA }}$ & $\Delta$ & $V_{0}^{O P T}$ & $V_{0}^{\text {OSLA }}$ & $\Delta$ \\
\hline 20 & 0 & 805 & 803 & $0.2 \%$ & 592 & 591 & $0.3 \%$ & 345 & 344 & $0.2 \%$ \\
20 & -10 & 104 & 104 & $0.5 \%$ & -29 & -29 & $0.9 \%$ & -85 & -85 & $0.1 \%$ \\
20 & 10 & 977 & 977 & $0.0 \%$ & 977 & 977 & $0.0 \%$ & 977 & 977 & $0.0 \%$ \\
10 & 0 & 694 & 692 & $0.3 \%$ & 417 & 415 & $0.5 \%$ & 152 & 151 & $0.7 \%$ \\
10 & -10 & -100 & -100 & $0.0 \%$ & -100 & -100 & $0.0 \%$ & -100 & -100 & $0.0 \%$ \\
10 & 10 & 977 & 977 & $0.0 \%$ & 977 & 977 & $0.0 \%$ & 977 & 977 & $0.0 \%$ \\
30 & 0 & 977 & 977 & $0.0 \%$ & 977 & 977 & $0.0 \%$ & 977 & 977 & $0.0 \%$ \\
30 & -10 & 237 & 236 & $0.4 \%$ & 35 & 34 & $1.6 \%$ & -64 & -64 & $0.2 \%$ \\
30 & 10 & 977 & 977 & $0.0 \%$ & 977 & 977 & $0.0 \%$ & 977 & 977 & $0.0 \%$ \\
\hline
\end{tabular}

Table 3 Performance of $O S L A$ hiring policy when $\beta=3$

Table 4 reports the discounted final cash $\delta^{N} I_{N}$ of the optimal policy and the $O S L A$ policy both when firing is frictionless $\left(F_{M}=F_{T}=0\right)$ and when firing is not allowed, in our base case of hiring frictions $\left(H_{M}=\$ 12,000\right.$ and $H_{T}=30$ days $)$ as well as when hiring is frictionless $\left(H_{M}=H_{T}=0\right)$, when $\beta=0.7, p=q=0.375$. As shown in the table, not allowing firing only leads to a marginal decline in performance. On the other hand, hiring frictions significantly affect performance.

Firing has little impact on performance here primarily because of our growth assumptions. In that setting, hiring accelerates growth; as a result, it is unlikely that, if the firm has hired an 


\begin{tabular}{|c|c|c|c|c|c|c|c|c|c|c|c|c|c|}
\hline & & \multicolumn{6}{|c|}{$H_{M}=\$ 12,000, H_{T}=30$ days } & \multicolumn{6}{|c|}{$H_{M}=\$ 0, H_{T}=0$ days } \\
\hline & & Frict & ionless $\mathrm{F}$ & iring & & To Firing & & Frict & onless $\mathrm{F}$ & iring & & To Firing & \\
\hline$I_{0}$ & $Z_{0}$ & $V_{0}^{O P T}$ & $V_{0}^{O S L A}$ & $\Delta$ & $V_{0}^{O P T}$ & $V_{0}^{O S L A}$ & $\Delta$ & $V_{0}^{O P T}$ & $V_{0}^{O S L A}$ & $\Delta$ & $V_{0}^{O P T}$ & $V_{0}^{O S L A}$ & $\Delta$ \\
\hline 20 & 0 & 346 & 346 & $0.2 \%$ & 346 & 345 & $0.2 \%$ & 977 & 977 & $0.0 \%$ & 977 & 977 & $0.0 \%$ \\
\hline 20 & -10 & -75 & -75 & $0.3 \%$ & -75 & -75 & $0.3 \%$ & 118 & 118 & $0.0 \%$ & 108 & 108 & $0.0 \%$ \\
\hline 20 & 10 & 974 & 974 & $0.0 \%$ & 974 & 974 & $0.0 \%$ & 977 & 977 & $0.0 \%$ & 977 & 977 & $0.0 \%$ \\
\hline 10 & 0 & 216 & 215 & $0.4 \%$ & 215 & 215 & $0.4 \%$ & 475 & 475 & $0.0 \%$ & 474 & 474 & $0.1 \%$ \\
\hline 10 & -10 & -100 & -100 & $0.0 \%$ & -100 & -100 & $0.0 \%$ & -100 & -100 & $0.0 \%$ & -100 & -100 & $0.0 \%$ \\
\hline 10 & 10 & 867 & 866 & $0.0 \%$ & 867 & 866 & $0.0 \%$ & 977 & 977 & $0.0 \%$ & 977 & 977 & $0.0 \%$ \\
\hline 30 & 0 & 546 & 545 & $0.1 \%$ & 546 & 545 & $0.1 \%$ & 977 & 977 & $0.0 \%$ & 977 & 977 & $0.0 \%$ \\
\hline 30 & -10 & -48 & -48 & $0.9 \%$ & -48 & -48 & $0.9 \%$ & 977 & 977 & $0.0 \%$ & 977 & 977 & $0.0 \%$ \\
\hline 30 & 10 & 977 & 977 & $0.0 \%$ & 977 & 977 & $0.0 \%$ & 977 & 977 & $0.0 \%$ & 977 & 977 & $0.0 \%$ \\
\hline
\end{tabular}

Table 4 Performance of $O S L A$ hiring policy with and without hiring frictions when $\beta=0.7, p=q=0.375$

employee, it would need to fire her at some point. Moreover, the state of the economy must be low if the firm needs to fire her employee. Given that successive states of the economy are positively correlated here, this implies that future states of the economy may also be low, and therefore that firing rarely helps avert going bankrupt. Given the low impact of firing on performance, we therefore conclude that treating them separately, as we did in our derivation of the OSLA policy in $\S 4$, can be done with no great loss of optimality when considering a growth-oriented firm, unlike established firms (Bentolila and Bertola 1990).

The sensitivity of both the OSLA and the optimal policies with respect to bankruptcy costs $K$ is shown in Tables 5 and 6 . Specifically, we consider $K=\$ 10,000,000$ and $K=\$ 0$ (the base case takes $K=\$ 100,000)$. We observe a marginal deterioration in the $O S L A$ performance when the bankruptcy cost is large and when the chance that the firm will not go bankrupt is moderate. (Even when the relative optimality loss may appear large, as when $I_{0}=\$ 30,000, Z_{0}=\$ 0, p=0.5$, and $q=0.25$ in Table 5, the absolute loss remains small, especially compared to the $\$ 10,000,000$ bankruptcy cost.) If it is clear that the firm will go bankrupt, then $O S L A$ performs as poorly as the optimal policy; and if it is clear that the firm will not go bankrupt, then the bankruptcy cost has minimal influence.

\subsection{Robustness}

How robust are the $O S L A$ thresholds to the model parameters? Table 7 displays the $O S L A$ hiring and firing thresholds for different values of the money and time elasticities $\alpha$ and $\beta$ and different values of $Z_{t} \cdot{ }^{5}$ Consistent with Proposition 3, the hiring thresholds are increasing in $Z_{t}$. (The firing upper thresholds are independent of $Z_{t}$, consistent with Proposition A-1 in the Appendix.) Moreover, the dependence of the hiring cash threshold on $Z_{t}$ appears almost linear, so $I_{H, t}^{O S L A}$ should

\footnotetext{
${ }^{5}$ Because the $O S L A$ hiring policy does not consider firing and vice versa, the $O S L A$ hiring cash threshold need not be larger than the $O S L A$ firing threshold, as when $Z_{t}$ is large. This does not mean that the entrepreneur should hire to fire: $Z_{t}$ is so large that the cash position after hiring will likely be above the firing threshold.
} 


\begin{tabular}{|c|c||r|r|r||r|r|r||r|r|r|}
\hline & \multicolumn{1}{|c||}{} & \multicolumn{2}{c||}{$p=0.5, q=0.25$} & \multicolumn{2}{c|}{$p=0.375, q=0.375$} & \multicolumn{3}{c|}{$p=0.25, q=0.5$} \\
\hline$I_{0}$ & $Z_{0}$ & $V_{0}^{O P T}$ & $V_{0}^{O S L A}$ & $\Delta$ & $V_{0}^{O P T}$ & $V_{0}^{O S L A}$ & $\Delta$ & $V_{0}^{O P T}$ & $V_{0}^{O S L A}$ & $\Delta$ \\
\hline 20 & 0 & -711 & -727 & $2.3 \%$ & $-3,204$ & $-3,237$ & $1.0 \%$ & $-6,302$ & $-6,335$ & $0.5 \%$ \\
20 & -10 & $-7,583$ & $-7,585$ & $0.0 \%$ & $-9,034$ & $-9,037$ & $0.0 \%$ & $-9,736$ & $-9,737$ & $0.0 \%$ \\
20 & 10 & 977 & 977 & $0.0 \%$ & 974 & 974 & $0.0 \%$ & 962 & 962 & $0.0 \%$ \\
10 & 0 & $-1,561$ & $-1,571$ & $0.6 \%$ & -4300 & $-4,323$ & $0.5 \%$ & $-7,232$ & $-7,259$ & $0.4 \%$ \\
10 & -10 & $-9,961$ & $-9,961$ & $0.0 \%$ & $-9,961$ & $-9,961$ & $0.0 \%$ & $-9,961$ & $-9,961$ & $0.0 \%$ \\
10 & 10 & 885 & 880 & $0.5 \%$ & 464 & 448 & $3.4 \%$ & -727 & -749 & $3.1 \%$ \\
30 & 0 & -76 & -113 & $49.7 \%$ & $-1,998$ & $-2,049$ & $2.6 \%$ & $-4,754$ & $-4,788$ & $0.7 \%$ \\
30 & -10 & $-5,980$ & $-5,987$ & $0.1 \%$ & $-8,258$ & $-8,266$ & $0.1 \%$ & $-9,499$ & $-9,504$ & $0.0 \%$ \\
30 & 10 & 977 & 977 & $0.0 \%$ & 977 & 977 & $0.0 \%$ & 977 & 977 & $0.0 \%$ \\
\hline
\end{tabular}

Table 5 Performance of $O S L A$ hiring policy when $\beta=0.7$ and $K=\$ 10,000,000$

\begin{tabular}{|c|c||r|r|r||r|r|r||r|r|r|}
\hline & \multicolumn{1}{|c||}{} & \multicolumn{2}{c||}{$p=0.5, q=0.25$} & \multicolumn{3}{c||}{$p=0.375, q=0.375$} & \multicolumn{3}{c|}{$p=0.25, q=0.5$} \\
\hline$I_{0}$ & $Z_{0}$ & $V_{0}^{O P T}$ & $V_{0}^{O S L A}$ & $\Delta$ & $V_{0}^{O P T}$ & $V_{0}^{O S L A}$ & $\Delta$ & $V_{0}^{O P T}$ & $V_{0}^{O S L A}$ & $\Delta$ \\
\hline 20 & 0 & 621 & 620 & $0.1 \%$ & 382 & 382 & $0.1 \%$ & 179 & 179 & $0.1 \%$ \\
20 & -10 & 58 & 58 & $0.9 \%$ & 15 & 15 & $1.5 \%$ & 2 & 2 & $2.2 \%$ \\
20 & 10 & 977 & 977 & $0.0 \%$ & 974 & 974 & $0.0 \%$ & 962 & 962 & $0.0 \%$ \\
10 & 0 & 493 & 492 & $0.1 \%$ & 261 & 260 & $0.3 \%$ & 99 & 99 & $0.3 \%$ \\
10 & -10 & 0 & 0 & $0.0 \%$ & 0 & 0 & $0.0 \%$ & 0 & 0 & $0.0 \%$ \\
10 & 10 & 946 & 946 & $0.0 \%$ & 871 & 871 & $0.0 \%$ & 729 & 729 & $0.0 \%$ \\
30 & 0 & 764 & 763 & $0.0 \%$ & 572 & 571 & $0.1 \%$ & 364 & 364 & $0.0 \%$ \\
30 & -10 & 116 & 115 & $0.8 \%$ & 35 & 35 & $1.1 \%$ & 6 & 6 & $1.4 \%$ \\
30 & 10 & 977 & 977 & $0.0 \%$ & 977 & 977 & $0.0 \%$ & 977 & 977 & $0.0 \%$ \\
\hline
\end{tabular}

Table 6 Performance of $O S L A$ hiring policy when $\beta=0.7$ and $K=\$ 0$

\begin{tabular}{|c||c|c||c|c|c|c|c|c|c|c|c|c|c|c|c|}
\hline \multicolumn{1}{l|}{} & \multirow{2}{*}{$\alpha$} & \multirow{2}{*}{$\beta$} & \multicolumn{10}{c|}{$Z_{t}$} \\
\cline { 5 - 15 } & & & -60 & -50 & -40 & -30 & -20 & -10 & 0 & 10 & 20 & 30 & 40 & 50 & 60 \\
\hline \hline \multirow{4}{*}{$I_{H, t}^{\text {OSLA }}$} & 0.99 & 0.7 & 94 & 84 & 74 & 64 & 53 & 43 & 33 & 22 & 12 & 1 & 1 & 1 & 1 \\
& 0.99 & 0.3 & 108 & 98 & 88 & 77 & 66 & 56 & 45 & 34 & 23 & 11 & 1 & 1 & 1 \\
& 0.99 & 3 & 86 & 76 & 66 & 56 & 46 & 35 & 25 & 15 & 6 & 1 & 1 & 1 & 1 \\
& 0.8 & 0.7 & 90 & 80 & 70 & 60 & 50 & 40 & 30 & 20 & 12 & 1 & 1 & 1 & 1 \\
\hline \hline \multirow{4}{*}{$\bar{I}_{F, t}^{\text {OSLA }}$} & 0.99 & 0.7 & 12 & 12 & 12 & 12 & 12 & 12 & 12 & 12 & 12 & 12 & 12 & 12 & 12 \\
& 0.99 & 0.3 & 23 & 23 & 23 & 23 & 23 & 23 & 23 & 23 & 23 & 23 & 23 & 23 & 23 \\
& 0.99 & 3 & 6 & 6 & 6 & 6 & 6 & 6 & 6 & 6 & 6 & 6 & 6 & 6 & 6 \\
& 0.8 & 0.7 & 12 & 12 & 12 & 12 & 12 & 12 & 12 & 12 & 12 & 12 & 12 & 12 & 12 \\
\hline
\end{tabular}

Table $7 \quad O S L A$ hiring and firing cash thresholds when $p=q=0.375$

not be too sensitive to the variance of $Z_{t}$ if its mean is properly estimated. Furthermore, $I_{H, t}^{O S L A}$ appears relatively robust to misspecifications of $\alpha$ and $\beta$, at least up to a limit: when the time elasticity falls below a certain level (e.g., when $\beta \leq 0.5$ if $\alpha=0.8$ ), the hiring threshold jumps to infinity, so it becomes optimal to never hire.

The high performance of the OSLA policy raises the question: How important is the timing of hiring? What are the consequences of hiring too early or too late? To address this question, we conduct the following experiment. For all $t$, we evaluate the expected revenue $\delta^{N} I_{N}$, averaged over 10,000 simulation runs, with an OSLA policy when the hiring cash thresholds are perturbed, i.e., 
Figure 7 Relative losses in optimality when the hiring cash thresholds are perturbed.
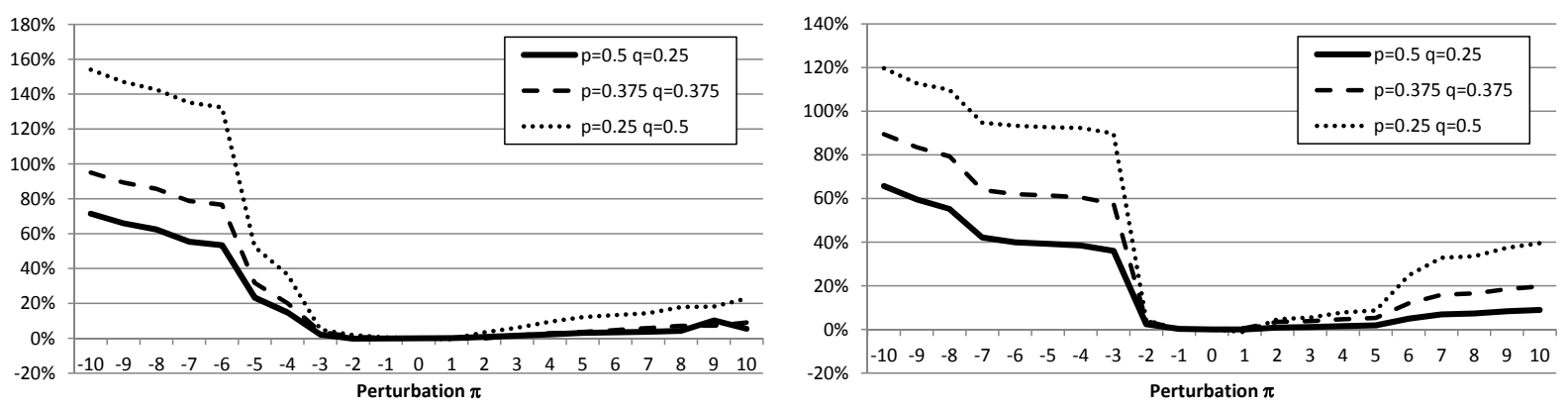

Note. $\left(H_{M}, H_{T}\right)=(\$ 12,000,30$ days $)$ (left) and $\left(H_{M}, H_{T}\right)=(\$ 6,000,15$ days $)$ (right).

by using $I_{H, t}^{O S L A}+\pi$, for all $t, \pi=-10, \cdots,+10$. Figure 7 depicts the relative loss of revenue from using cash thresholds $I_{H, t}^{O S L A}+\pi$ instead of $I_{H, t}^{O S L A}$, when $p=0.5$ and $q=0.25$ (solid), $p=0.375$ and $q=0.375$ (dashed), and $p=0.25$ and $q=0.5$ (dotted) for high hiring cost and time (left) and low hiring cost and time (right).

Overall, the figure shows that the hiring cash thresholds are relatively robust when the cash thresholds are overestimated. By contrast, underestimating the hiring cash thresholds can lead to a significant loss of revenue. The risks involved in hiring are highly asymmetric: while hiring too late (high $I_{H, t}^{O S L A}$ ) hurts performance only moderately, hiring too early (low $I_{H, t}^{O S L A}$ ) can have severe consequences, potentially precipitating the entrepreneur into bankruptcy. The asymmetry in the optimality loss curve is consistent with our result that in a deterministic environment the OSLA hiring cash threshold is a lower bound on the optimal hiring threshold (Proposition 5(i)). Overall, Figure 7 indicates that the optimal threshold is relatively insensitive to perturbations, so reasonable approximations such as the $O S L A$ cash threshold should perform well.

\section{Conclusions}

In this paper, we study how growth in small entrepreneurial firms is affected by two key constraints: money and time. The two resources are asymmetric in that (i) money, unlike time, is fungible, and (ii) the primary output of the firm is money, not time. We introduce a model of growth, which depends on complementary inputs of money and time, explore the consequences of this asymmetry, and how entrepreneurs can trade time and money.

First, we establish that as the firm grows, there is a fundamental shift in the bottleneck from money to time. Hiring is then a natural mechanism to trade off less valuable money for more valuable time, thereby increasing capacity to accelerate growth.

Second, we characterize the timing of hiring in terms of a cash level threshold via a one-stagelook-ahead $(O S L A)$ policy. We numerically demonstrate that this $O S L A$ policy performs well and show that it is optimal under deterministic growth. The high performance of the OSLA policy is 
driven by the growth conditions and bootstrapping strategy inherent in our context. This suggests that the hiring of subsequent employees may also be timed in an $O S L A$ fashion, similar to the timing of the first employee, provided that these growth conditions continue to hold.

Unlike established firm settings of capacity expansion or staffing, for growth-oriented firms, the entrepreneur's time is critical for growth and thus cannot implicitly be converted into money. In particular, we show that unlike hiring costs, which always delay the timing of hiring, greater hiring times may delay or expedite the timing of hiring. This is due to two opposing effects: an increase in hiring time yields slower growth pushing for hiring later, but the entrepreneur wants to incur the higher hiring time when her time is less valuable, pushing for hiring earlier.

To sustain growth, entrepreneurs must effectively marshal their key resources, such as time and money. Managing operations in these growth settings requires properly identifying the bottleneck resource at specific points in time and putting in place strategies to alleviate them.

\section{References}

Aldrich, H.E., C.M. Fiol. 1994. Fools rush in? The institutional context of industry creation. Academy of Management Review. 19(4), 645-670.

Angelus, A., E.L. Porteus. 2002. Simultaneous capacity and production management of short-life-cycle, produce-to-stock goods under stochastic demand. Management Science. 48(3), 399-413.

Archibald, T.W., L.C. Thomas, J.M. Betts, R.B. Johnston. 2002. Should start-up companies be cautious? Inventory policies which maximize survival probabilities. Management Science, 48(9) 1161-1174.

Babich, V., M.J. Sobel. 2004. Pre-IPO operational and financial decisions. Management Science 50(7), 935948.

Bentolila, S., G. Bertola. 1990. Firing costs and labour demand: How bad is Eurosclerosis? The Review of Economic Studies, 57(3), 381-402.

Berger, A. N., G. F. Udell. 1998. The economics of small business finance: The role of private equity and debt markets in the financial growth cycle. Journal of Banking and Finance, 22(6-8), 613-673.

Bertsekas, D.P. 2000. Dynamic Programming and Optimal Control, Volume 1. Athena Scientific, Belmont, MA. Second Edition.

Bitran, G.R., E.A. Haas, A.C. Hax. 1981. Hierarchical production planning: A single stage system. Operations Research, 29(4), 717-743.

Boyd, S., L. Vandenberghe. 2004. Convex Optimization. Cambridge University Press, Cambridge, UK.

Burgstone, J. and Murphy Jr, B. 2012. Breakthrough Entrepreneurship. Farallon Publishing. San Francisco, CA.

Buzacott, J.A., R.Q. Zhang. 2004. Inventory management with asset-based financing. Management Science, 50(9), 1274-1292. 
Caldentey, R., M. Haugh. 2006. Optimal control and hedging of operations in the presence of financial markets. Mathematics of Operations Research. 31(2), 285-304.

Churchill, N.C., V.L. Lewis. 1983. The five stages of small business growth. Harvard Business Review, MayJune, 1983.

Collins, C.J., K.D. Clark. 2003. Strategic human resource practices, top management team social networks, and firm performance: The role of human resource practices in creating organizational competitive advantage. Academy of Management Journal, 46(6), 740-751.

Cressy, R. 1996. Are business startups debt-rationed?. The Economic Journal, 106(438), 1253-1270.

Dada, M., Q. Hu. 2008. Financing newsvendor inventory. Operations Research Letters, 36(5), 569-573.

Dixit, A.K., R.S. Pindyck. 1994. Investment Under Uncertainty. Princeton University Press, Princeton, NJ.

Dupuy, A., A. de Grip. 2006. Elasticity of substitution and productivity, capital and skill intensity differences across firms. Economic Letters 90(3), 340-347.

Ebben, J., A. Johnson. 2006. Bootstrapping in small firms: An empirical analysis of change over time. Journal of Business Venturing, 21(6), 851-865.

Evans, D.S., B. Jovanovic. 1989. An estimated model of entrepreneurial choice under liquidity constraints. Journal of Political Economy, 97(4), 808-827.

Gans, N., Y.P. Zhou. 2002. Managing learning and turnover in employee staffing. Operations Research, 50(6), 991-1006.

Garmaise, M. J.. 2008. Production in entrepreneurial firms: The effects of financial constraints on labor and capital. The Review of Financial Studies, 21(2), 543-577.

Gifford, S. 1992. Allocation of entrepreneurial attention. Journal of Economic Behavior and Organization, 19(3), 256-284.

Goldratt, E. M.. 2004. The Goal: A Process of Ongoing Improvement. North River Press.

Hambrick, D.C., L.M. Crozier. 1985. Stumblers and stars in the management of rapid growth. Journal of Business Venturing, 1(1), 31-45.

Hamermesh, R.G., J.L. Heskett, M.J. Roberts. 2005. A note on managing the growing venture. Harvard Business School Case, 9-805-092.

Hess, E.D. 2012. Grow to Greatness. Stanford University Press. Stanford, CA.

Holt, C.C., F. Modigliani, J.F. Muth, H.A. Simon. 1960. Planning Production, Inventories, and Workforce. Prentice-Hall, Englewood Cliffs, NJ.

Hu, Q., M. Sobel. 2005. Capital structure and inventory management. Case Western University Working Paper.

Jovanovic, B. 1982. Selection and the evolution of industry. Econometrica, 50(3), 649-670. 
Kouvelis, P., W. Zhao. 2011. The newsvendor problem and price-only contract when bankruptcy costs exist. Production and Operations Management, 26(6), 921-936.

Krishnan, V. 2013. Operations management opportunities in technology commercialization and entrepreneurship. Production and Operations Management, Forthcoming.

Lévesque, M., C. Schade. 2005. Intuitive optimizing: Experimental findings on time allocation decisions with newly formed ventures. Journal of Business Venturing, 20(3), 313-342.

Lévesque, M., K. MacCrimmon. 1997. On the interaction of time and money invested in new ventures. Entrepreneurship Theory and Practice, 22(2), 89-110.

Li, L. 1988. A stochastic theory of the firm. Mathematics of Operations Research, 13(3), 447-466.

Li, L, M. Shubik, M. Sobel. 2009. Control of dividends, capital subscriptions, and physical inventories. Case Western Reserve University Working Paper.

Luss, H. 1982. Operations research and capacity expansion problems: A survey. Operations Research, 30(5), 907-947.

Manne, A. 1961. Capacity expansion and probabilistic growth. Econometrica, 29(4), 632-649.

Martin, B., T. Papadimitriou. 2009. Are You the Bottleneck in Your Organization? Retrieved December 8, 2009, from http://blogs.hbr.org/cs/2009/12/

Mueler, S., Volery, T., and von Siemens, B. 2012. What do entrepreneurs actusally do? An observational study of entrepreneurs' everyday behavior in the start-up and growth stages. Entrepreneurship Theory and Practice, 36(5), 995-1017.

Phillips, B.D., B.A. Kirchhoff. 1989. Formation, growth and survival. Small firm dynamics in the US economy. Small Business Economics, 1(1), 65-74.

Quinn, R.E., K. Cameron. 1983. Organizational life cycles and shifting criteria of effectiveness: Some preliminary evidence. Management Science, 29(1), 33-51.

Radner, R., L. Shepp. 1996. Risk vs. profit potential: A model for corporate strategy. Journal of Economic Dynamics and Control, 20(8), 1373-1393.

Shepp, L., A. Shiryaev. 1996. Hiring and firing optimally in a large corporation. Journal of Economic Dynamics and Control, 20(9-10), 1523-1539.

Silver, E.A., D.F. Pyke, R. Peterson. 1998. Inventory Management and Production Planning and Scheduling. John Wiley \& Sons, New York, NY.

Sobel, M., D. Turcic. 2007. Coordination of inventory, capital and dividends in nascent firms. Case Western Reserve University Working Paper.

Swinney, R., G. Cachon, S. Netessine. 2011. Capacity investment timing by start-ups and established firms in new markets. Management Science, 57(4), 763-777. 
Tanrisever, F., S. Erzurumulu, N. Joglekar. 2012. Production, process improvement and the survival of debt fincanced startup firms. Production and Operations Management, Forthcoming.

Tansky, J.W., R.L. Heneman. 2006. Human Resource Strategies for the High Growth Entrepreneurial Firm. Information Age Publishing, Inc., Greenwich, CT.

Topkis, D.M. 1998. Supermodularity and Complementarity. Princeton University Press, New Jersey.

Van Mieghem, J.A. 2003. Capacity management, investment, and hedging: Review and recent developments. Manufacturing 8 Service Operations Management, 5(4), 269-302.

Williamson, I.O. 2000. Employer legitimacy and recruitment success in small business. Entrepreneurship: Theory and Practice, 25: 27-42.

$\mathrm{Xu}$, X., J. Birge. 2006. Equity valuation, production, and financial planning: A stochastic programming approach. Naval Resarch Logistics, 53(7), 641-655.

Ye, Q., I. Duenyas. 2007. Optimal capacity investment decisions with two-sided fixed capacity adjustment costs. Operations Research, 55(2): 272-284.

Yoo, O.S., C.J. Corbett, G. Roels. 2011. Dynamic Process Improvement for Growth: Optimal Time Allocation Policy for Entrepreneurs. Working Paper.

\section{Appendix}

Lemma A-1. $V_{t}^{0}\left(I_{t}, J_{t}, Z_{t}\right)$ is increasing in $I_{t}$.

Proof. The proof is by induction on $t$. By (1), when $t=N, V_{N}^{0}\left(I_{N}, J_{N}, Z_{N}\right)=I_{N}$ if $I_{N}>L$ and it is equal to $-K$ otherwise. Fix $t$ and suppose that $V_{t+1}^{0}\left(I_{t+1}, J_{t+1}, Z_{t+1}\right)$ is increasing in $I_{t+1}$. Let $I^{+}>I^{-}$. Suppose that $I^{-} \geq L$. Then, using (1),

$$
\begin{aligned}
V_{t}^{0}\left(I^{+}, J_{t}, Z_{t}\right) & =\max _{M_{t}, T_{t} \leq J_{t}} \delta \mathbb{E}_{\omega_{t}}\left[V_{t+1}^{0}\left((1+r) I^{+}+\Pi\left(M_{t}, T_{t} \mid I^{+}, Z_{t}\right), J_{t+1}, \phi_{t}\left(Z_{t}, \omega_{t}\right)\right]\right. \\
& \geq \max _{M_{t}, T_{t} \leq J_{t}} \delta \mathbb{E}_{\omega_{t}}\left[V_{t+1}^{0}\left((1+r) I^{-}+\Pi\left(M_{t}, T_{t} \mid I^{-}, Z_{t}\right), J_{t+1}, \phi_{t}\left(Z_{t}, \omega_{t}\right)\right]=V_{t}^{0}\left(I^{-}, J_{t}, Z_{t}\right),\right.
\end{aligned}
$$

in which the inequality follows by induction hypothesis and because $\Pi\left(M_{t}, T_{t} \mid I, Z_{t}\right)$ is increasing in $I$ since $B(M, I, Z)$ is decreasing in $I$. If $I^{-}<L$, then $V_{t}^{0}\left(I^{-}, J_{t}, Z_{t}\right)=-K \leq V_{t}^{0}\left(I^{+}, J_{t}, Z_{t}\right)$ by assumption on $K$, with equality only if $I^{+}<L$.

Proof of Lemma 1. By Lemma A-1, maximizing $\delta \mathbb{E}_{\omega_{t}}\left[V_{t+1}^{0}\left((1+r) I_{t}+\Pi\left(M_{t}, T_{t} \mid I_{t}, Z_{t}\right), J_{t+1}, \phi_{t}\left(Z_{t}, \omega_{t}\right)\right]\right.$ with respect to $\left(M_{t}, T_{t}\right)$ is equivalent to maximizing $\Pi\left(M_{t}, T_{t} \mid I_{t}, Z_{t}\right)$.

LEMma A-2. (i) $\Pi^{*}(I, J, Z)$ has increasing differences in $(I, J)$; (ii) $\Pi^{*}(I, J, Z)$ is concave increasing in $(I, J)$.

Proof. (i) The function $\Pi(M, T \mid I, Z)$ is supermodular in $(M, T, I)$ since the sum of supermodular functions is supermodular (Lemma 2.6.1 in Topkis 1998) and since (i) $R(M, T, Z)$ is supermodular in $(M, T)$, (ii) $B(M, I, Z)$ is submodular in $(M, I)$, (iii) $[M-I]^{+}$is submodular in $(M,-I)$ since it is a convex increasing 
transformation of an isotone valuation in $(M, I)$ by Lemma 2.6.4 in Topkis (1998). Because $\Pi(M, T \mid I, Z)$ is supermodular in $(M, T, I)$, and because the feasible set of $T$ is increasing in $J$ respectively, the result follows from Theorem 2.7.6 in Topkis (1998).

(ii) When maximized over $T \leq J, \Pi(M, T \mid I, Z)=\Pi(M, J \mid I, Z)$ since $\Pi(M, T \mid I, Z)$ is increasing in $J$. The function $\Pi(M, J \mid I, Z)$ is concave in $(M, J, I)$ since $B(M, I, Z)$ is convex in $(M, I)$ and $R(M, J, Z)$ is concave in $(M, J)$. Because concavity is preserved under maximization over convex sets (Boyd and Vandenberghe $2004), \Pi^{*}(I, J, Z)$ is concave in $(I, J)$.

Proof of Proposition 1. To simplify notations, we assume that $\Pi^{*}(I, J, Z)$ is differentiable in $(I, J)$. Applying the chain rule to (1) and using Lemma 1, we obtain:

$$
\begin{aligned}
\tau_{t} & =\frac{\partial}{\partial J} V_{t}^{0}\left(I_{t}, J_{t}, Z_{t}\right) \\
& =\delta \frac{\partial}{\partial I} \mathbb{E}_{\omega_{t}}\left[V_{t+1}^{0}\left((1+r) I_{t}+\Pi^{*}\left(I_{t}, J_{t}, Z_{t}\right), J_{t+1}, \phi_{t}\left(Z_{t}, \omega_{t}\right)\right)\right] \frac{\partial}{\partial J} \Pi^{*}\left(I_{t}, J_{t}, Z_{t}\right), \text { and } \\
\mu_{t} & =\frac{\partial}{\partial I} V_{t}^{0}\left(I_{t}, J_{t}, Z_{t}\right)-\delta \frac{\partial}{\partial I} \mathbb{E}_{\omega_{t}}\left[V_{t+1}^{0}\left(I_{t+1}, J_{t+1}, \phi_{t}\left(Z_{t}, \omega_{t}\right)\right)\right] \\
& =\delta \frac{\partial}{\partial I} \mathbb{E}_{\omega_{t}}\left[V_{t+1}^{0}\left((1+r) I_{t}+\Pi^{*}\left(I_{t}, J_{t}, Z_{t}\right), J_{t+1}, \phi_{t}\left(Z_{t}, \omega_{t}\right)\right)\right] \frac{\partial}{\partial I} \Pi^{*}\left(I_{t}, J_{t}, Z_{t}\right) .
\end{aligned}
$$

Hence $\mu_{t}>\tau_{t}$ if and only if $\partial \Pi^{*}\left(I_{t}, J_{t}, Z_{t}\right) / \partial I_{t}-\partial \Pi^{*}\left(I_{t}, J_{t}, Z_{t}\right) / \partial J_{t}>0$. Because $\Pi^{*}(I, J, Z)$ is concave in $(I, J)$ and has increasing differences in $(I, J)$ by Lemma A-2, the left-hand side is decreasing in $I_{t}$ and increasing in $J_{t}$. When $I_{t}<L, M_{t}=0$ for otherwise $B\left(M_{t}, I_{t}, Z_{t}\right)=\infty$ by assumption, and therefore $\Pi^{*}\left(I_{t}, J_{t}, Z_{t}\right)=$ $R\left(0, J_{t}, Z_{t}\right)=R\left(0,0, Z_{t}\right)$. Hence, $\partial \Pi^{*}\left(I_{t}, J_{t}, Z_{t}\right) / \partial I_{t}=0$ for all $I_{t}<L$, and the left-hand side is nonnegative by Lemma A-2(ii). On the other hand, when $I_{t} \rightarrow \infty, \Pi^{*}\left(I_{t}, J_{t}, Z_{t}\right)=\max _{M_{t}, T_{t} \leq J_{t}} R\left(M_{t}, T_{t}, Z_{t}\right)-(1+r) M_{t}$ since $\lim _{I \rightarrow \infty} B(M, I, Z) \leq B(M, M, Z)=0$. Hence, $\lim _{I_{t} \rightarrow \infty} \partial \Pi^{*}\left(I_{t}, J_{t}, Z_{t}\right) / \partial I_{t}=0$, and the left-hand side is nonpositive by Lemma A-2(ii). Hence, there exists a cash threshold $\hat{I}$ such that $\tau_{t}<\mu_{t}$ if and only if $I_{t}<\hat{I}$.

When $J_{t}=0, \partial \Pi^{*}\left(I_{t}, J_{t}, Z_{t}\right) / \partial I_{t}=0$ since $\Pi^{*}\left(I_{t}, 0, Z_{t}\right)=\max _{M_{t}} R\left(M, 0, Z_{t}\right)-(1+r) M-B\left(M, I, Z_{t}\right)+$ $(1+r)[M-I]^{+} \leq R\left(0,0, Z_{t}\right)$; in that case, the left-hand side is nonpositive by Lemma A-2(ii). On the other hand, when $J_{t} \rightarrow \infty, \partial \Pi^{*}\left(I_{t}, J_{t}, Z_{t}\right) / \partial J_{t}=0$, and the left-hand side is nonnegative by Lemma A-2(ii). Hence, there exists a time threshold $\hat{J}$ such that $\tau_{t}<\mu_{t}$ if and only if $J_{t}>\hat{J}$.

Lemma A-3. $V_{t}\left(E_{t}, I_{t}, Z_{t}\right)$ is increasing in $I_{t}$.

Proof. The proof is similar to the proof of Lemma A-1.

Lemma A-4. For any $y \geq H_{T}, g_{H}(I, J, Z)-f(I, J, Z)$ is increasing in $I$ and decreasing in $J$.

Proof. Define $y \equiv y-H_{T} \geq 0$ and $w \equiv w+H_{M} \geq 0$. Fix $\epsilon>0$. By Lemma A-2, $\Pi^{*}(I, J, Z)$ is concave in $I$ and has increasing differences in $(I, J)$. Accordingly,

$$
\begin{aligned}
\Pi^{*}(I+\epsilon-w, J+y, Z)-\Pi^{*}(I-w, J+y, Z) & \geq \Pi^{*}(I+\epsilon, J+y, Z)-\Pi^{*}(I, J+y, Z) \\
& \geq \Pi^{*}(I+\epsilon, J, Z)-\Pi^{*}(I, J, Z) .
\end{aligned}
$$

Hence, $\Pi^{*}(I, J, Z)-\Pi^{*}(I-w, J+y, Z) \geq \Pi^{*}(I+\epsilon, J, Z)-\Pi^{*}(I+\epsilon-w, J+y, Z)$, i.e., $\Pi^{*}(I, J, Z)-\Pi^{*}(I-$ $w, J+y, Z)$ is decreasing in $I$. Using the fact that $\Pi^{*}(I, J, Z)$ is concave in $I$ and has increasing differences in $(I, J)$ by Lemma A-2, the proof that $\Pi^{*}(I, J, Z)-\Pi^{*}(I-w, J+y, Z)$ is increasing in $J$ follows a similar argument. 
Lemma A-5. If $f\left(I, J_{t}, Z_{t}\right) \leq g_{H}\left(I, J_{t}, Z_{t}\right)+H_{M}$, then $g_{H}\left(f\left(I_{t}, J_{t}, Z_{t}\right), J_{t+1}, Z_{t+1}\right) \leq$ $h\left(g_{H}\left(I_{t}, J_{t}, Z_{t}\right), J_{t+1}, Z_{t+1}\right)$.

Proof. We have:

$$
\begin{aligned}
& g_{H}\left(f\left(I_{t}, J_{t}, Z_{t}\right), J_{t+1}, Z_{t+1}\right)-h\left(g_{H}\left(I_{t}, J_{t}, Z_{t}\right), J_{t+1}, Z_{t+1}\right) \\
= & (1+r)\left(f\left(I_{t}, J_{t}, Z_{t}\right)-w-H_{M}\right)-(1+r)\left(g_{H}\left(I_{t}, J_{t}, Z_{t}\right)-w\right) \\
& +\Pi^{*}\left(f\left(I_{t}, J_{t}, Z_{t}\right)-w-H_{M}, J_{t+1}+y-H_{T}, Z_{t+1}\right)-\Pi^{*}\left(g_{H}\left(I_{t}, J_{t}, Z_{t}\right)-w, J_{t+1}+y, Z_{t+1}\right) \\
\leq & \Pi^{*}\left(g_{H}\left(I_{t}, J_{t}, Z_{t}\right)-w, J_{t+1}+y-H_{T}, Z_{t+1}\right)-\Pi^{*}\left(g_{H}\left(I_{t}, J_{t}, Z_{t}\right)-w, J_{t+1}+y, Z_{t+1}\right) \leq 0,
\end{aligned}
$$

in which the first inequality follows because $\Pi^{*}(I, J, Z)$ is increasing in $I$ by Lemma A-2 and since $f\left(I_{t}, J_{t}, Z_{t}\right) \leq g_{H}\left(I_{t}, J_{t}, Z_{t}\right)+H_{M}$, and the second inequality follows because $\Pi^{*}(I, J, Z)$ is increasing in $J$ by Lemma A-2.

Lemma A-6. Under Assumption 1, when $f\left(I_{t}, J_{t}, Z_{t}\right) \geq g_{H}\left(I_{t}, J_{t}, Z_{t}\right)+H_{M}, g_{H}\left(f\left(I_{t}, J_{t}, Z_{t}\right), J_{t+1}, Z_{t+1}\right)-$ $h\left(g_{H}\left(I_{t}, J_{t}, Z_{t}\right), J_{t+1}, Z_{t+1}\right)$ is decreasing in $I_{t}$.

Proof. We use equation (A-1). By Assumption 1, $f(I, J, z)-g_{H}(I, J, Z)$ is decreasing in $I$. Fix $\epsilon>0$. By Lemma A-2, $\Pi^{*}(I, J, Z)$ has increasing differences in $(I, J)$ and is concave increasing in $I$. Hence,

$$
\begin{aligned}
& \Pi^{*}\left(g_{H}\left(I_{t}+\epsilon, J_{t}, Z_{t}\right)-w, J_{t+1}+y, Z_{t+1}\right)-\Pi^{*}\left(g_{H}\left(I_{t}, J_{t}, Z_{t}\right)-w, J_{t+1}+y, Z_{t+1}\right) \\
\geq & \Pi^{*}\left(g_{H}\left(I_{t}+\epsilon, J_{t}, Z_{t}\right)-w, J_{t+1}+y-H_{T}, Z_{t+1}\right)-\Pi^{*}\left(g_{H}\left(I_{t}, J_{t}, Z_{t}\right)-w, J_{t+1}+y-H_{T}, Z_{t+1}\right) \\
\geq & \Pi^{*}\left(f\left(I_{t}+\epsilon, J_{t}, Z_{t}\right)+g_{H}\left(I_{t}, J_{t}, Z_{t}\right)-f\left(I_{t}, J_{t}, Z_{t}\right)-w, J_{t+1}+y-H_{T}, Z_{t+1}\right) \\
& -\Pi^{*}\left(g_{H}\left(I_{t}, J_{t}, Z_{t}\right)-w, J_{t+1}+y-H_{T}, Z_{t+1}\right) \\
\geq & \Pi^{*}\left(f\left(I_{t}+\epsilon, J_{t}, Z_{t}\right)-w-H_{M}, J_{t+1}+y-H_{T}, Z_{t+1}\right)-\Pi^{*}\left(f\left(I_{t}, J_{t}, Z_{t}\right)-w-H_{M}, J_{t+1}+y-H_{T}, Z_{t+1}\right),
\end{aligned}
$$

in which the first inequality follows because $g(I, J, Z)$ is increasing in $I$ and because $\Pi^{*}(I, J, Z)$ is increasing in $I$ and has increasing differences in $(I, J)$; the second is because $\Pi^{*}(I, J, Z)$ is increasing in $I$ and $g_{H}\left(I_{t}, J_{t}, Z_{t}\right)-$ $f\left(I_{t}, J_{t}, Z_{t}\right)$ is increasing in $I_{t}$ by Assumption 1; and the last inequality follows because $\Pi^{*}(I, J, Z)$ is concave in $I$ and $f\left(I_{t}, J_{t}, Z_{t}\right) \geq g_{H}\left(I_{t}, J_{t}, Z_{t}\right)+H_{M}$. Hence, $\Pi^{*}\left(f\left(I_{t}, J_{t}, Z_{t}\right)-w-H_{M}, J_{t+1}+y-H_{T}, Z_{t+1}\right)-$ $\Pi^{*}\left(g_{H}\left(I_{t}, J_{t}, Z_{t}\right)-w, J_{t+1}+y, Z_{t+1}\right)$ is decreasing in $I_{t}$.

Proof of Lemma 2. Suppose that $I_{t}>I_{H, t}^{O S L A}$. Because $\Pi^{*}(I, J, Z)$ is increasing in $I$ by Lemma A2, $g_{H}\left(I_{t}, J_{t}, Z_{t}\right) \geq L$. By Assumption 1, there exists a threshold $\bar{I}$ such that $g_{H}\left(I, J_{t}, Z_{t}\right)+H_{M}>$ $f\left(I, J_{t}, Z_{t}\right)$ if and only $I>\bar{I}$. We consider two cases. First, suppose that $I_{t} \geq \bar{I}$. Then, by Lemma A-5, $g_{H}\left(f\left(I_{t}, J_{t}, Z_{t}\right), J_{t+1}, Z_{t+1}\right) \leq h\left(g_{H}\left(I_{t}, J_{t}, Z_{t}\right), J_{t+1}, Z_{t+1}\right)$ for all $Z_{t+1}$. Second, suppose that $I_{t} \leq \bar{I}$, and therefore, that $I_{H, t}^{O S L A}<\bar{I}$. Then, by Lemma A-6,

$$
\begin{aligned}
& \mathbb{E}_{\omega_{t}}\left[g_{H}\left(f\left(I_{t}, J_{t}, Z_{t}\right), J_{t+1}, \phi_{t}\left(Z_{t}, \omega_{t}\right)\right)-h\left(g_{H}\left(I_{t}, J_{t}, Z_{t}\right), J_{t+1}, \phi_{t}\left(Z_{t}, \omega_{t}\right)\right)\right] \\
\leq & \mathbb{E}_{\omega_{t}}\left[g_{H}\left(f\left(I_{H, t}^{O S L A}, J_{t}, Z_{t}\right), J_{t+1}, \phi_{t}\left(Z_{t}, \omega_{t}\right)\right)-h\left(g_{H}\left(I_{H, t}^{O S L A}, J_{t}, Z_{t}\right), J_{t+1}, \phi_{t}\left(Z_{t}, \omega_{t}\right)\right)\right] \leq 0 .
\end{aligned}
$$

Hence, hiring in period $t$ maximizes $I_{t+2}$. The proof for the case in which $I_{t}<I_{H, t}^{O S L A}$ is similar. 
Proof of Proposition 2. The proof applies the implicit function theorem to the equations $\operatorname{defining} I_{H, t}^{O S L A}$. Suppose that $g_{H}\left(I_{H, t}^{O S L A}, J_{t}, Z_{t}\right)=L$. Then, $I_{H, t}^{O S L A}$ is independent of $J_{t+1}$.

Suppose next that $G\left(I_{H, t}^{O S L A}, J_{t+1}\right) \equiv \mathbb{E}_{\omega_{t}}\left[g_{H}\left(f\left(I_{H, t}^{O S L A}, J_{t}, Z_{t}\right), J_{t+1}, \phi_{t}\left(Z_{t}, \omega_{t}\right)\right)-\right.$ $\left.h\left(g_{H}\left(I_{H, t}^{O S L A}, J_{t}, Z_{t}\right), J_{t+1}, \phi_{t}\left(Z_{t}, \omega_{t}\right)\right)\right]=0$. By Lemma A-5, we must have that $g_{H}\left(I_{H, t}^{O S L A}, J_{t}, Z_{t}\right)+H_{M} \leq$ $f\left(I_{H, t}^{O S L A}, J_{t}, Z_{t}\right)$. Hence by Lemma A-6, $G\left(I_{H, t}^{O S L A}, J_{t+1}\right)$ is decreasing in $I_{t}$. For each $\omega_{t} \in \Omega_{t}$, when $g_{H}\left(I, J_{t}, Z_{t}\right)+H_{M} \leq f\left(I, J_{t}, Z_{t}\right)$, we have

$$
\begin{aligned}
& \frac{\partial g_{H}\left(f\left(I, J_{t}, Z_{t}\right), J_{t+1}, \phi_{t}\left(Z_{t}, \omega_{t}\right)\right)}{\partial J}-\frac{\partial h\left(g_{H}\left(I, J_{t}, Z_{t}\right), J_{t+1}, \phi_{t}\left(Z_{t}, \omega_{t}\right)\right)}{\partial J} \\
= & \frac{\partial \Pi^{*}\left(f\left(I, J_{t}, Z_{t}\right)-H_{M}-w, J_{t+1}+y-H_{T}, \phi_{t}\left(Z_{t}, \omega_{t}\right)\right)}{\partial J}-\frac{\partial \Pi^{*}\left(g_{H}\left(I, J_{t}, Z_{t}\right)-w, J_{t+1}+y, \phi_{t}\left(Z_{t}, \omega_{t}\right)\right)}{\partial J} \\
\geq & \frac{\partial \Pi^{*}\left(g_{H}\left(I, J_{t}, Z_{t}\right)-w, J_{t+1}+y-H_{T}, \phi_{t}\left(Z_{t}, \omega_{t}\right)\right)}{\partial J}-\frac{\partial \Pi^{*}\left(g_{H}\left(I, J_{t}, Z_{t}\right)-w, J_{t+1}+y, \phi_{t}\left(Z_{t}, \omega_{t}\right)\right)}{\partial J} \\
\geq & \frac{\partial \Pi^{*}\left(g_{H}\left(I, J_{t}, Z_{t}\right)-w, J_{t+1}+y, \phi_{t}\left(Z_{t}, \omega_{t}\right)\right)}{\partial J}-\frac{\partial \Pi^{*}\left(g_{H}\left(I, J_{t}, Z_{t}\right)-w, J_{t+1}+y, \phi_{t}\left(Z_{t}, \omega_{t}\right)\right)}{\partial J} \geq 0,
\end{aligned}
$$

in which the first inequality follows because $\Pi^{*}(I, J, Z)$ has increasing differences in $(I, J)$ by Lemma A-2 and because $f\left(I_{t}, J_{t}, Z_{t}\right) \geq g_{H}\left(I_{t}, J_{t}, Z_{t}\right)+H_{M}$; and the second inequality follows because $\Pi^{*}(I, J, Z)$ is concave in $J$ by Lemma A-2. Hence, $G\left(I_{H, t}^{O S L A}, J_{t+1}\right)$ is increasing in $J_{t+1}$.

Suppose now that $H_{T}=H_{M}=0$ and $L=-\infty$. Suppose that $\mathbb{E}_{\omega_{t}}\left[g_{H}\left(f\left(I_{H, t}^{O S L A}, J_{t}, Z_{t}\right), J_{t+1}, \phi_{t}\left(Z_{t}, \omega_{t}\right)\right)-\right.$ $\left.h\left(g_{H}\left(I_{H, t}^{O S L A}, J_{t}, Z_{t}\right), J_{t+1}, \phi_{t}\left(Z_{t}, \omega_{t}\right)\right)\right]=0$, i.e., $G\left(I_{H, t}^{O S L A}, J_{t}\right) \equiv f\left(I_{H, t}^{O S L A}, J_{t}, Z_{t}\right)-h\left(I_{H, t}^{O S L A}, J_{t}, Z_{t}\right)=0$ since $g_{H}()=.h($.$) . Since \Pi(I, J, Z)$ is concave in $I$ and has increasing differences in $(I, J), G\left(I_{H, t}^{O S L A}, J_{t}\right)$ is decreasing in $I$ and increasing in $J_{t}$, i.e., $I_{H, t}^{O S L A}$ is increasing in $J_{t}$.

Proof of Proposition 3. The proof applies the implicit function theorem to the equations defining $I_{H, t}^{O S L A}$. Suppose that $I_{H, t}^{O S L A}$ solves $g_{H}\left(I, J_{t}, Z_{t}\right)=L$. Because the left-hand side is increasing in $I$ by Lemma A-2 and increasing in $Z$, we obtain that $d I_{t}^{O S L A} / d Z_{t} \leq 0$.

Suppose next that $G\left(I_{H, t}^{O S L A}, J_{t+1}\right) \equiv \mathbb{E}_{\omega_{t}}\left[g_{H}\left(f\left(I_{H, t}^{O S L A}, J_{t}, Z_{t}\right), J_{t+1}, \phi_{t}\left(Z_{t}, \omega_{t}\right)\right)-\right.$ $\left.h\left(g_{H}\left(I_{H, t}^{O S L A}, J_{t}, Z_{t}\right), J_{t+1}, \phi_{t}\left(Z_{t}, \omega_{t}\right)\right)\right]=0$. By Lemma A-5, we must have that $g_{H}\left(I_{H, t}^{O S L A}, J_{t}, Z_{t}\right)+H_{M} \leq$ $f\left(I_{H, t}^{O S L A}, J_{t}, Z_{t}\right)$. Hence by Lemma A-6, $G\left(I_{H, t}^{O S L A}, J_{t+1}\right)$ is decreasing in $I_{t}$. For each $\omega_{t} \in \Omega_{t}$, when $g_{H}\left(I, J_{t}, Z_{t}\right)+H_{M} \leq f\left(I, J_{t}, Z_{t}\right)$, we have

$$
\begin{aligned}
& \frac{\partial g_{H}\left(f\left(I, J_{t}, Z_{t}\right), J_{t+1}, \phi_{t}\left(Z_{t}, \omega_{t}\right)\right)}{\partial I} \frac{\partial f\left(I, J_{t}, Z_{t}\right)}{\partial Z}-\frac{\partial h\left(g_{H}\left(I, J_{t}, Z_{t}\right), J_{t+1}, \phi_{t}\left(Z_{t}, \omega_{t}\right)\right)}{\partial I} \frac{\partial g_{H}\left(I, J_{t}, Z_{t}\right)}{\partial Z} \\
& +\frac{\partial \phi_{t}\left(Z_{t}, \omega_{t}\right)}{\partial Z}\left(\frac{\partial g_{H}\left(f\left(I, J_{t}, Z_{t}\right), J_{t+1}, \phi_{t}\left(Z_{t}, \omega_{t}\right)\right)}{\partial Z}-\frac{\partial h\left(g_{H}\left(I, J_{t}, Z_{t}\right), J_{t+1}, \phi_{t}\left(Z_{t}, \omega_{t}\right)\right)}{\partial Z}\right) \\
= & \frac{\partial g_{H}\left(I, J_{t}, Z_{t}\right)}{\partial Z}\left(\frac{\partial \Pi^{*}\left(f\left(I, J_{t}, Z_{t}\right)-w-H_{M}, J_{t+1}+y-H_{T}, \phi_{t}\left(Z_{t}, \omega_{t}\right)\right)}{\partial I}-\frac{\partial \Pi^{*}\left(g_{H}\left(I, J_{t}, Z_{t}\right)-w, J_{t+1}+y, \phi_{t}\left(Z_{t}, \omega_{t}\right)\right)}{\partial I}\right) \\
\leq & \frac{\partial g_{H}\left(I, J_{t}, Z_{t}\right)}{\partial Z}\left(\frac{\partial \Pi^{*}\left(f\left(I, J_{t}, Z_{t}\right)-w-H_{M}, J_{t+1}+y, \phi_{t}\left(Z_{t}, \omega_{t}\right)\right)}{\partial I}-\frac{\partial \Pi^{*}\left(g_{H}\left(I, J_{t}, Z_{t}\right)-w, J_{t+1}+y, \phi_{t}\left(Z_{t}, \omega_{t}\right)\right)}{\partial I}\right) \\
\leq & \frac{\partial g_{H}\left(I, J_{t}, Z_{t}\right)}{\partial Z}\left(\frac{\partial \Pi^{*}\left(g_{H}\left(I, J_{t}, Z_{t}\right)-w, J_{t+1}+y, \phi_{t}\left(Z_{t}, \omega_{t}\right)\right)}{\partial I}-\frac{\partial \Pi^{*}\left(g_{H}\left(I, J_{t}, Z_{t}\right)-w, J_{t+1}+y, \phi_{t}\left(Z_{t}, \omega_{t}\right)\right)}{\partial I}\right)=0,
\end{aligned}
$$

in which the first equality is because of Assumption 2; the first inequality follows because $\Pi^{*}(I, J, Z)$ has increasing differences in $(I, J)$ by Lemma A-2 and $g_{H}\left(I, J_{t}, Z_{t}\right)$ is increasing in $Z_{t}$; and the second inequality follows because $\Pi^{*}(I, J, Z)$ is concave in $I$ by Lemma A-2 and because $f\left(I_{t}, J_{t}, Z_{t}\right) \geq g_{H}\left(I_{t}, J_{t}, Z_{t}\right)+H_{M}$. Therefore, $G\left(I_{H, t}^{O S L A}, Z_{t}\right)$ is decreasing in $Z_{t}$.

Summarizing, we obtain that $I_{H, t}^{O S L A}$ is decreasing in $Z_{t}$. 
Proof of Proposition 4. The proof applies the implicit function theorem to the equations $\operatorname{defining} I_{H, t}^{O S L A}$. Suppose that $I_{H, t}^{O S L A}$ solves $g_{H}\left(I, J_{t}, Z_{t}\right)=L$. Because the left-hand side is increasing in $I$ and decreasing in $H_{T}$ and $H_{M}$ by Lemma A-2, we obtain that $d I_{H, t}^{O S L A} / d H_{M} \geq 0$ and $d I_{H, t}^{O S L A} / d H_{T} \geq 0$ in that case.

Next, suppose that $G\left(I_{H, t}^{O S L A}, J_{t+1}\right) \equiv \mathbb{E}_{\omega_{t}}\left[g_{H}\left(f\left(I_{H, t}^{O S L A}, J_{t}, Z_{t}\right), J_{t+1}, \phi_{t}\left(Z_{t}, \omega_{t}\right)\right) \quad-\right.$ $\left.h\left(g_{H}\left(I_{H, t}^{O S L A}, J_{t}, Z_{t}\right), J_{t+1}, \phi_{t}\left(Z_{t}, \omega_{t}\right)\right)\right]=0$. By Lemma A-5, we must have that $g_{H}\left(I_{H, t}^{O S L A}, J_{t}, Z_{t}\right)+H_{M} \leq$ $f\left(I_{H, t}^{O S L A}, J_{t}, Z_{t}\right)$. Hence by Lemma A-6, $G\left(I_{H, t}^{O S L A}, J_{t+1}\right)$ is decreasing in $I_{t}$.

(i) For each $\omega_{t} \in \Omega_{t}$, when $g_{H}\left(I, J_{t}, Z_{t}\right)+H_{M} \leq f\left(I, J_{t}, Z_{t}\right)$, we have

$$
\begin{aligned}
& \frac{\partial g_{H}\left(f\left(I, J_{t}, Z_{t}\right), J_{t+1}, \phi_{t}\left(Z_{t}, \omega_{t}\right)\right)-h\left(g_{H}\left(I, J_{t}, Z_{t}\right), J_{t+1}, \phi_{t}\left(Z_{t}, \omega_{t}\right)\right)}{\partial H_{M}} \\
= & r(1+r)+(1+r) \frac{\partial \Pi^{*}\left(I_{t}-H_{M}-w, J-H_{T}+y, Z_{t}\right)}{\partial I}-\frac{\partial \Pi^{*}\left(f\left(I_{t}, Z_{t}\right)-H_{M}-w, J-H_{T}+y, Z_{t+1}\right)}{\partial I} \\
& +\frac{\partial \Pi^{*}\left(g_{H}\left(I_{t}, Z_{t}\right)-w, J+y, Z_{t+1}\right)}{\partial I}\left(1+r+\frac{\partial \Pi^{*}\left(I_{t}-H_{M}-w, J-H_{T}+y, Z_{t}\right)}{\partial I}\right) \\
\geq & r(1+r)+(1+r) \frac{\partial \Pi^{*}\left(I_{t}-H_{M}-w, J-H_{T}+y, Z_{t}\right)}{\partial I} \\
& +\frac{\partial \Pi^{*}\left(g_{H}\left(I_{t}, Z_{t}\right)-w, J+y, Z_{t+1}\right)}{\partial I}\left(r+\frac{\partial \Pi^{*}\left(I_{t}-H_{M}-w, J-H_{T}+y, Z_{t}\right)}{\partial I}\right) \geq 0 .
\end{aligned}
$$

in which the first inequality follows because $\Pi^{*}(I, J, Z)$ has increasing differences in $(I, J)$ and concave in $I$ by Lemma A-2, and because $f\left(I_{t}, J_{t}, Z_{t}\right) \geq g_{t}\left(I_{t}, J_{t} Z_{t}\right)+H_{M}$ when $I_{t}=I_{H, t}^{O S L A}$. Hence, $G\left(I_{H, t}^{O S L A}, H_{M}\right)$ is increasing in $H_{M}$. Therefore, $d I_{H, t}^{O S L A} / d H_{M} \geq 0$

(ii) Consider the derivative of the function with respect to $H_{T}$ :

$$
\begin{aligned}
& \frac{\partial g_{H}\left(f\left(I, J_{t}, Z_{t}\right), J_{t+1}, \phi_{t}\left(Z_{t}, \omega_{t}\right)\right)-h\left(g_{H}\left(I, J_{t}, Z_{t}\right), J_{t+1}, \phi_{t}\left(Z_{t}, \omega_{t}\right)\right)}{\partial H_{T}} \\
= & \left(1+r+\frac{\partial \Pi^{*}\left(g_{H}\left(I, J_{t}, Z_{t}\right)-w, J+y, Z_{t+1}\right)}{\partial I}\right) \frac{\partial \Pi^{*}\left(I-H_{M}-w, J-H_{T}+y, Z_{t}\right)}{\partial J} \\
& -\frac{\partial \Pi^{*}\left(f\left(I, J_{t}, Z_{t}\right)-H_{M}-w, J-H_{T}+y, Z_{t+1}\right)}{\partial J} \equiv \mathcal{G}\left(H_{T}\right) .
\end{aligned}
$$

If $f\left(I_{H, t}^{O S L A}, J_{t}, Z_{t}\right) \leq I_{H, t}^{O S L A}$, then $\mathcal{G}\left(H_{T}\right) \geq 0$ at $I_{H, t}^{O S L A}$ given that $\Pi^{*}(I, J, Z)$ has increasing differences in $(I, J)$ and is increasing in $(I, J)$ by Lemma A-2, and that $\partial \Pi^{*}(I, J, Z) / \partial J$ is independent of $Z$ by assumption.

Next suppose that $f\left(I_{H, t}^{O S L A}, J_{t}, Z_{t}\right)>I_{H, t}^{O S L A}$. When $\mathcal{G}\left(H_{T}\right)=0$,

$$
\begin{aligned}
\mathcal{G}^{\prime}\left(H_{T}\right)= & -\left(1+r+\frac{\partial \Pi^{*}\left(g_{H}\left(I, J_{t}, Z_{t}\right)-w, J+y, Z_{t+1}\right)}{\partial I}\right) \frac{\partial^{2} \Pi^{*}\left(I-H_{M}-w, J-H_{T}+y, Z_{t}\right)}{\partial J^{2}} \\
& +\frac{\partial^{2} \Pi^{*}\left(f\left(I, J_{t}, Z_{t}\right)-H_{M}-w, J-H_{T}+y, Z_{t+1}\right)}{\partial J^{2}} \\
& -\frac{\partial^{2} \Pi^{*}\left(g_{H}\left(I, Z_{t}\right)-w, J+y, Z_{t+1}\right)}{\partial I^{2}}\left(\frac{\partial \Pi^{*}\left(I-w-H_{M}, J-H_{T}+y, Z_{t}\right)}{\partial J}\right)^{2} \\
= & -\left(\frac{\left.\frac{\partial \Pi^{*}\left(f\left(I, J_{t}, Z_{t}\right)-H_{M}-w, J-H_{T}+y, Z_{t+1}\right)}{\partial J}\right)}{\frac{\partial \Pi^{*}\left(I-H_{M}-w, J-H_{T}+y, Z_{t}\right)}{\partial J}}\right) \frac{\partial^{2} \Pi^{*}\left(I-H_{M}-w, J-H_{T}+y, Z_{t}\right)}{\partial J^{2}} \\
& +\frac{\partial^{2} \Pi^{*}\left(f\left(I, J_{t}, Z_{t}\right)-H_{M}-w, J-H_{T}+y, Z_{t+1}\right)}{\partial J^{2}} \quad\left(\frac{\partial \Pi^{*}\left(I-w-H_{M}, J-H_{T}+y, Z_{t}\right)}{\partial J}\right)^{2} \geq 0, \\
& -\frac{\partial^{2} \Pi^{*}\left(g_{H}\left(I, J_{t}, Z_{t}\right)-w, J+y, Z_{t+1}\right)}{\partial I^{2}}\left(\frac{\partial}{\partial \Pi^{*}(I J, Z)}\right)
\end{aligned}
$$

in which the inequality follows because $\frac{\partial^{2} \Pi^{*}(I, J, Z)}{\partial J^{2}} / \frac{\partial \Pi^{*}(I, J, Z)}{\partial J}$ is increasing in $I$ by assumption and is independent of $Z$ by Assumption 2, because $f\left(I, J_{t}, Z_{t}\right) \geq I$ by assumption, and because $\Pi^{*}(I, J, Z)$ is concave in 
$I$ by Lemma A-2. Hence, $\mathcal{G}\left(H_{T}\right)$ crosses zero at most once, and if it does, it crosses it from below. Applying the implicit function theorem to $g_{H}\left(f\left(I_{t}^{O S L A}, J_{t}, Z_{t}\right), J_{t+1}, Z_{t+1}\right)-h\left(g_{H}\left(I_{t}^{O S L A}, J_{t}, Z_{t}\right), J_{t+1}, Z_{t+1}\right)$ thus shows that there exists a $\chi$ such that $d I_{t}^{O S L A} / d H_{T} \geq 0$ if and only if $H_{T} \geq \chi$.

Lemma A-7. Under Assumptions 1 and 2 and when $\left|\Omega_{t+k}\right|=1$ for all $k \geq 0$, if it is optimal to hire in period $t$, then $I_{t} \geq I_{H, t}^{O S L A}$.

Proof. Suppose that $I_{t}<I_{H, t}^{O S L A}$. Following the same logic as in Lemma 2, we must then have either that $g_{H}\left(I_{t}, J_{t}, Z_{t}\right)<L$, or that $\mathbb{E}_{\omega_{t}}\left[g_{H}\left(f\left(I_{t}, J_{t}, Z_{t}\right), J_{t+1}, \phi_{t}\left(Z_{t}, \omega_{t}\right)\right)\right]>\mathbb{E}_{\omega_{t}}\left[h\left(g_{H}\left(I_{t}, J_{t}, Z_{t}\right), J_{t+1}, \phi_{t}\left(Z_{t}, \omega_{t}\right)\right)\right]$. Suppose the latter. By Assumption 2, we thus have that $g_{H}\left(f\left(I_{t}, J_{t}, Z_{t}\right), J_{t+1}, Z_{t+1}\right)>h\left(g_{H}\left(I_{t}, J_{t}, Z_{t}\right), J_{t+1}, Z_{t+1}\right)$. Then by (4) and Lemma A-3,

$$
\begin{aligned}
V_{t+1}\left(0, f\left(I_{t}, J_{t}, Z_{t}\right), J_{t+1}, Z_{t+1}\right) & \geq \delta V_{t+2}\left(1, g_{H}\left(f\left(I_{t}, J_{t}, Z_{t}\right), J_{t+1}, Z_{t+1}\right), Z_{t+2}\right) \\
& >\delta V_{t+2}\left(1, h\left(g_{H}\left(I_{t}, J_{t}, Z_{t}\right), J_{t+1}, Z_{t+1}\right), Z_{t+2}\right)=V_{t+1}\left(1, g_{H}\left(I_{t}, J_{t}, Z_{t}\right), J_{t+1}, Z_{t+1}\right),
\end{aligned}
$$

in which the first inequality follows because hiring is feasible in period $t+1$, and the second follows because $V_{t+2}\left(1, I_{t+2}, Z_{t+2}\right)$ is increasing in $I_{t+2}$ by Lemma A-3. Hence, it is optimal to not hire in period $t$.

Lemma A-8. Suppose that $\left|\Omega_{t}\right|=1$ for all $t$. If $I_{t} \geq I_{H, t}$, in which

$$
I_{H, t} \equiv \min \left\{I \mid I \geq I_{H, t}^{O S L A}, f\left(I, J_{t}, Z_{t}\right) \geq I_{H, t+1}^{O S L A}, \ldots, f\left(f\left(\cdots f\left(f\left(I, J_{t}, Z_{t}\right), J_{t+1}, Z_{t+1}\right) \cdots\right), J_{N-3}, Z_{N-3}\right) \geq I_{H, N-2}^{O S L A}\right\},
$$

then it is more profitable to hire in period t than in any other period.

Proof. To simplify notation, define $f_{t}(I) \equiv f\left(I, J_{t}, Z_{t}\right), g_{t}(I) \equiv g_{H}\left(I, J_{t}, Z_{t}\right)$, and $h(I) \equiv h_{t}\left(I, J_{t}, Z_{t}\right)$. Fix $t$. Suppose that $I_{t} \geq I_{H, t}$. The proof proceeds by induction, rolling the horizon $N$ forward, by showing that it is optimal to hire in period $t$ when the horizon is equal to $t+k, k=2, \ldots, N-t$. Fix $t$ and suppose that $N=t+2$. Because $I_{t} \geq I_{H, t} \geq I_{H, t}^{O S L A}$, it is optimal to hire in $t$ when $N=t+2$, i.e., $h_{t+1}\left(g_{t}(I)\right)>g_{t+1}\left(f_{t}(I)\right)$.

Suppose next that it is optimal to hire in period $t$ to maximize $I_{N-1}$. Hence, we must have that

$$
\begin{gathered}
h_{N-2}\left(h_{N-3}\left(\cdots h_{t+1}\left(g_{t}\left(I_{t}\right)\right) \cdots\right)\right) \geq \max \left\{h_{N-2}\left(h_{N-3}\left(\cdots g_{t+1}\left(f_{t}\left(I_{t}\right)\right), \cdots\right)\right), h_{N-2}\left(h_{N-3}\left(\cdots f_{t+1}\left(f_{t}\left(I_{t}\right)\right) \cdots\right)\right), \cdots,\right. \\
\left.h_{N-2}\left(g_{N-3}\left(\cdots f_{t+1}\left(f_{t}\left(I_{t}\right)\right) \cdots\right)\right), g_{N-2}\left(f_{N-3}\left(\cdots f_{t+1}\left(f_{t}\left(I_{t}\right)\right)\right)\right)\right\} .
\end{gathered}
$$

Because the function $h_{N-1}(I)$ is increasing by Lemma A-2, we obtain, by applying the function $h_{N-1}($. to the induction hypothesis,

$$
\begin{gathered}
h_{N-1}\left(h_{N-2}\left(h_{N-3}\left(\cdots h_{t+1}\left(g_{t}\left(I_{t}\right)\right) \cdots\right)\right)\right) \geq \max \left\{h_{N-1}\left(h_{N-2}\left(h_{N-3}\left(\cdots g_{t+1}\left(f_{t}\left(I_{t}\right)\right), \cdots\right)\right)\right),\right. \\
\left.h_{N-1}\left(h_{N-2}\left(h_{N-3}\left(\cdots f_{t+1}\left(f_{t}\left(I_{t}\right)\right) \cdots\right)\right)\right), \cdots, h_{N-1}\left(g_{N-2}\left(f_{N-3}\left(\cdots f_{t+1}\left(f_{t}\left(I_{t}\right)\right) \cdots\right)\right)\right)\right\} .
\end{gathered}
$$

Moreover, we obtain that

$$
\begin{aligned}
& h_{N-1}\left(h_{N-2}\left(h_{N-3}\left(\cdots h_{t+1}\left(g_{t}\left(I_{t}\right)\right) \cdots\right)\right)\right) \geq h_{N-1}\left(h_{N-2}\left(h_{N-3}\left(\cdots h_{t+2}\left(g_{t+1}\left(f_{t}\left(I_{t}\right)\right)\right) \cdots\right)\right)\right) \\
\geq & h_{N-1}\left(h_{N-2}\left(h_{N-3}\left(\cdots g_{t+2}\left(f_{t+1}\left(f_{t}\left(I_{t}\right)\right)\right) \cdots\right)\right)\right) \geq \cdots \geq h_{N-1}\left(g_{N-2}\left(f_{N-3}\left(\cdots f_{t+1}\left(f_{t}\left(I_{t}\right)\right) \cdots\right)\right)\right) \\
\geq & g_{N-1}\left(f_{N-2}\left(f_{N-3}\left(\cdots f_{t+1}\left(f_{t}\left(I_{t}\right)\right) \cdots\right)\right)\right) .
\end{aligned}
$$

since $I_{t} \geq I_{H, t}^{O S L A}, f_{t}\left(I_{t}\right) \geq I_{H, t+1}^{O S L A}, \cdots, f_{N-3}\left(\cdots f_{t+1}\left(f_{t}\left(I_{t}\right)\right) \cdots\right) \geq I_{H, N-2}^{O S L A}$. Hence, it is more profitable to hire in period $t$ when the horizon is equal to $N$. 
Proof of Proposition 5. The necessary condition is obtained from Lemma A-7. The sufficient condition is obtained from Lemma A-8 by showing that $I_{H, t}=I_{H, t}^{O S L A}$. Under Assumption 2 and when $J_{t}=J, I_{H, t}^{O S L A}$ is decreasing in $Z_{t}$ as shown in Proposition 3, but is otherwise time-independent. Because $Z_{t+1} \geq Z_{t}$, we have that $I_{H, t}^{O S L A} \geq I_{H, t+1}^{O S L A}$. If moreover $f(I, J, Z) \geq I$, it is therefore sufficient to have $I \geq I_{H, t}^{O S L A}$ for the conditions $f\left(I, J_{t}, Z_{t}\right) \geq I_{H, t+1}^{O S L A}, \ldots, f\left(f\left(\cdots f\left(f\left(I, J_{t}, Z_{t}\right), J_{t+1}, Z_{t+1}\right) \cdots\right), J_{N-3}, Z_{N-3}\right) \geq I_{H, N-2}^{O S L A}$ to be satisfied.

Lemma A-9. For any $w \geq F_{M}, g_{F}(I, J, Z)-h(I, J, Z)$ is decreasing in $I$.

Proof. The proof is similar to the proof of Lemma A-4.

Lemma A-10. Suppose that $F_{T}=0$. Then $g_{F}\left(I, J_{t}, Z_{t}\right) \leq h\left(I, J_{t}, Z_{t}\right)-F_{M}$ if and only if $f\left(g_{F}\left(I_{t}, J_{t}, Z_{t}\right), J_{t+1}, Z_{t+1}\right) \leq g_{F}\left(h\left(I_{t}, J_{t}, Z_{t}\right), J_{t+1}, Z_{t+1}\right)$.

Proof. The proof immediately follows from the fact that $f\left(I-F_{M}, J_{t+1}, Z_{t+1}\right)=g_{F}\left(I, J_{t+1}, Z_{t+1}\right)$.

Proof of Lemma 3. Suppose that $I_{t}>\underline{I}_{F, t}^{O S L A}$. Then, $g_{F}\left(I_{t}, J_{t}, Z_{t}\right) \geq L$ since $\Pi^{*}(I, J, Z)$ is increasing in $I$ by Lemma A-2. Suppose that $I_{t}<\bar{I}_{F, t}^{O S L A}$. Under Assumption 3, $g_{F}\left(I_{t}, J_{t}, Z_{t}\right)-h\left(I_{t}, J_{t}, Z_{t}\right) \geq$ $g_{F}\left(\bar{I}_{F, t}^{O S L A}, J_{t}, Z_{t}\right)-h\left(\bar{I}_{F, t}^{O S L A}, J_{t}, Z_{t}\right)$. By definition, $g_{F}\left(\bar{I}_{F, t}^{O S L A}, J_{t}, Z_{t}\right) \geq h\left(\bar{I}_{F, t}^{O S L A}, J_{t}, Z_{t}\right)-F_{M}$, for otherwise we would have had $f\left(g_{F}\left(\bar{I}_{F, t}^{O S L A}, J_{t}, Z_{t}\right), J_{t+1}, Z_{t+1}\right)<g_{F}\left(h\left(\bar{I}_{F, t}^{O S L A}, J_{t}, Z_{t}\right), J_{t+1}, Z_{t+1}\right)$ by Lemma A-10. Hence, $g_{F}\left(I, J_{t}, Z_{t}\right) \geq h\left(I, J_{t}, Z_{t}\right)-F_{M}$ for all $I \in\left[I_{t}, \bar{I}_{F, t}^{O S L A}\right]$. By Lemma A-10, we must thus have that $\mathbb{E}_{\omega_{t}}\left[f\left(g_{F}\left(I_{t}, J_{t}, Z_{t}\right), J_{t+1}, \phi_{t}\left(Z_{t}, \omega_{t}\right)\right)-g_{F}\left(h\left(I_{t}, J_{t}, Z_{t}\right), J_{t+1}, \phi_{t}\left(Z_{t}, \omega_{t}\right)\right)\right] \geq 0$.

Lemma A-11. Under Assumption 3 and when $\left|\Omega_{t+k}\right|=1$ for all $k \geq 0$, if it is optimal to fire in period $t$, then $\underline{I}_{F, t}^{O S L A} \leq I_{t} \leq \bar{I}_{F, t}^{O S L A}$.

Proof. Suppose that $I_{t}<\underline{I}_{F, t}^{O S L A}$. Because $\Pi^{*}(I, J, Z)$ is increasing in $I, g_{F}\left(I_{t}, J_{t}, Z_{t}\right)<L$, i.e., the firm goes bankrupt if it fires. Suppose next that $I_{t}>\bar{I}_{F, t}^{O S L A}$. Following the same logic as in Lemma 3, we must then have that $h\left(I_{t}, J_{t}, Z_{t}\right)-F_{M}>g_{F}\left(I_{t}, J_{t}, Z_{t}\right)$. Then by (4) and Lemma A-3,

$$
\begin{aligned}
V_{t+1}\left(1, h\left(I_{t}, J_{t}, Z_{t}\right), J_{t+1}, Z_{t+1}\right) & \geq \delta V_{t+2}\left(0, g_{F}\left(h\left(I_{t}, J_{t}, Z_{t}\right), J_{t+1}, Z_{t+1}\right), Z_{t+2}\right) \\
& >\delta V_{t+2}\left(0, f\left(g_{F}\left(I_{t}, J_{t}, Z_{t}\right), J_{t+1}, Z_{t+1}\right), Z_{t+2}\right)=V_{t+1}\left(0, g_{F}\left(I_{t}, J_{t}, Z_{t}\right), J_{t+1}, Z_{t+1}\right)
\end{aligned}
$$

in which the first inequality follows because firing is feasible in period $t+1$, and the second follows because $V_{t+2}\left(1, I_{t+2}, Z_{t+2}\right)$ is increasing in $I_{t+2}$ by Lemma A-3. Hence, it is optimal to not fire in period $t$.

Proof of Proposition 6. The necessary condition is obtained from Lemma A-11. Similar to Lemma A-8, one can show that it is more profitable to fire that employee in period $t$ rather than in any other future period if $\underline{I}_{F, t}^{O S L A}<I_{t}<\bar{I}_{F, t}^{O S L A}, h\left(I_{t}, J_{t}, Z_{t}\right)<\bar{I}_{F, t+1}^{O S L A}, \cdots, h\left(h\left(\cdots h\left(h\left(I, J_{t}, Z_{t}\right), J_{t+1}, Z_{t+1}\right) \cdots\right), J_{N-3}, Z_{N-3}\right) \leq \bar{I}_{F, N-2}^{O S L A}$. If $h\left(I, J_{t+k}, Z_{t+k}\right) \leq I$ and if $\bar{I}_{F, t+k+1}^{O S L A} \geq \bar{I}_{F, t+k}^{O S L A}$ for all $k \geq 0$, it is then sufficient that $\underline{I}_{F, t}^{O S L A}<I_{t}<\bar{I}_{F, t}^{O S L A}$ for those conditions to be satisfied. By Proposition A-1, $\bar{I}_{F, t+k+1}^{O S L A} \geq \bar{I}_{F, t+k}^{O S L A}$ is satisfied when either $J_{t+k}=J_{t}$ or $J_{t+k} \geq J_{t}$ and $F_{M} \geq w$.

Proposition A-1 (Sensitivity of OSLA Firing Policy). Suppose that Assumption 3 holds. Then, $\underline{I}_{F, t}^{O S L A}$ is decreasing in $J_{t}$ and $Z_{t}$, and increasing in $F_{M}$. On the other hand, $\bar{I}_{F, t}^{O S L A}$ is decreasing in $F_{M}$ and, if $F_{M} \leq w$, is increasing in $J_{t}$, and when Assumption 2 holds, is independent of $Z_{t}$. 
Proof of Proposition A-1. The proof applies the implicit function theorem to the following equations: $g_{F}\left(\underline{I}_{F, t}^{O S L A}, J_{t}, Z_{t}\right)=L$ and $g_{F}\left(\bar{I}_{F, t}^{O S L A}, J_{t}, Z_{t}\right)-h\left(\bar{I}_{F, t}^{O S L A}, J_{t}, Z_{t}\right)+F_{M}=0$. Consider first $g_{F}\left(\underline{I}_{F, t}^{O S L A}, J_{t}, Z_{t}\right)=L$. The left-hand side is increasing in $I_{t}$ by Lemma A-2, and therefore decreasing in $F_{M}$, and also increasing in $J_{t}$ and $Z_{t}$. Consider next $g_{F}\left(\bar{I}_{F, t}^{O S L A}, J_{t}, Z_{t}\right)-h\left(\bar{I}_{F, t}^{O S L A}, J_{t}, Z_{t}\right)+F_{M}=0$. By Assumption 3 , the left-hand side is decreasing in $I_{t}$. The left-hand side is decreasing in $F_{M}$ and, under Assumption 2, independent of $Z_{t}$. When $F_{M} \leq w$, the left-hand side is increasing in $J_{t}$ by Lemma A-2. 